\title{
FEM prediction of welding residual stresses in fibre laser welded AA 2024-T3 and comparison with experimental measurement
}

\author{
J. Ahn ${ }^{*}$, E. He ${ }^{2}$, L. Chen ${ }^{2}$, R. C. Wimpory ${ }^{3}$, S. Kabra ${ }^{4}$, J. P. Dear ${ }^{1}$ and C. M. Davies ${ }^{1}$ \\ ${ }^{1}$ Department of Mechanical Engineering, Imperial College London, South Kensington Campus, London, UK \\ SW7 2AZ \\ ${ }^{2}$ Science and Technology on Power Beam Lab, Beijing Aeronautical Manufacturing Technology Research \\ Institute, China \\ ${ }^{3}$ Helmholtz-Zentrum Berlin, Hahn-Meitner-Platz 1, D-14109 Berlin, Germany \\ ${ }^{4}$ ISIS, Science and Technology Facilities Council, Rutherford Appleton Laboratory, Didcot, Oxfordshire, UK, \\ OX11 0QX
}

\section{Abstract}

Welding generates a considerable amount of residual stresses which affect the structural integrity of welded components. It is often assumed that the magnitude of residual stresses around the welded joint is as high as the yield stress of the material. In this investigation, such assumption was found to be overly conservative and failed to accurately represent the distribution of residual stresses in fibre laser welded aluminium alloy 2024-T3 sheets. Welding simulation based on the finite element method was used to reliably determine the distribution and magnitude of transient residual stress fields and distortions in thin sheets welded using three different sets of welding parameters. The accuracy of the finite element models was checked by calibrating with experimentally measured weld pool geometries and temperature field prior to conducting parametric studies. X-ray and neutron diffraction measurements were performed on the surface and in the bulk of the welded components, respectively and compared with numerical results. The influence of weld metal softening, welding parameters and restraints on residual stresses and distortion were investigated systematically by numerically simulating ideal conditions which eliminate the practical limitations of conducting experimental studies, for process optimization as well as evaluation of in-service structure integrity and failure modes of the welded sheets.

\section{Keywords}

Residual stress; Aluminium alloys; Lasers; Welding; Neutron diffraction; Numerical simulation

*corresponding author: joseph.ahn08@imperial.ac.uk; Tel: +44 7948532667 


\section{Introduction}

The aircraft industry has long recognised the importance of climate protection and the benefits of reducing weight to produce cost-effective and fuel-efficient aircraft structures. Fibre laser welding provides advantages over conventional riveting, mainly in terms of weight reduction and time-saving. However, significant changes in microstructure, metallurgical state and associated mechanical properties occur in welded joints. Such changes can result in residual stresses, distortions and defect formation in the welded structure, thus significantly influencing the performance and service life. To maintain the structural integrity of welded structures, the relationship between welding process and structural performance needs to be fully assessed.

Aluminium alloys are known for their unique high strength to density ratio and stiffness superior to steel, making them suitable and popular for airframe construction. The 2024 alloy is often used in the T3 temper as naturally ageing alone provides high ratios of tensile to yield strength particularly at elevated temperatures, ductility, fracture toughness and fatigue resistance but increase susceptibility to stress corrosion cracking. Still, cold working after solid solution and before ageing improves strength and stress corrosion resistance of the 2024 alloy by increasing the number of nucleation sites for age hardening precipitates.

The 2024 alloy, however, is known to be difficult to weld due to its susceptibility to cracking and porosity formation. Welding defects such as cracks and porosities pose a significant risk to the welded parts since they tend to weaken the structure by introducing stress concentrations around the defects. These defects often occur when the power density of the welding process is not high enough or due to residual stresses [1]. In addition, steep temperature gradients in the fusion zone trigger vaporisation and loss of some alloying elements in aluminium alloy, which may degrade its mechanical properties. The formation of porosity during welding increases the tendency for the welded structures to fail or even fracture $[2,3]$. However, these barriers can be mitigated by optimizing the power density and heat input, both of which can be controlled by the laser source parameters such as laser power, welding speed, focal position, etc.

There is currently limited research addressing the feasibility of fibre laser welding AA 2024T3. Some of the earlier research conducted includes the work by Chen et al. [4] and Ahn et al. [4-7] who examined the influence of various welding parameters on the microstructure and 
mechanical properties of AA 2024-T3 fibre laser welds and identified the optimum sets of welding parameters. This paper develops further the investigations performed by the aforementioned authors to produce full penetration butt welds in thin sheets of $3 \mathrm{~mm}$ AA 2024-T3 of a quality acceptable for aircraft structures according to the specifications provided in the European standards ISO 13919-1 [8], ISO 13919- 2 [9], and the American standard AWS D17.1 [10]. The ability to laser weld AA 2024-T3 alloy would allow, for example, the replacement of the 6000 series alloys used for integral aircraft fuselage structures, which are more weldable but at the same time, have lower strength, fatigue resistance and damage tolerance with the 2024-T3 alloy and also enable the use of thinner sections and decrease weight while maintaining the strength and stiffness of structures equivalent to those manufactured using the 6000 series alloys [11, 12].

Fibre laser welding leads to less distortion and residual stress than conventional fusion welding processes due to its lower overall heat input. Nevertheless, some residual stresses are formed which can have negative effects on integrity, fracture toughness, load capacity, stress corrosion resistance, fatigue life and fatigue crack initiation and propagation of the welded component under cyclic loading [13, 14]. Tensile residual stresses could lead to brittle failure or accelerated crack growth near the weld region and decrease the tolerance against externally applied loads [15]. Distortion can also pose serious problems since the shape of the final component is affected. The main distortion mode in welded thin sheets is an out-ofplane distortion caused by angular change and cambering along the weld centreline. However, in thin sheets, the angular distortion is not significant due to the relatively small through thickness temperature gradient [16].

To predict the service life of welded structures accurately, it is necessary to understand the residual stress distribution in the material. Recent advances in both numerical simulation and experimental measurement of residual stresses have allowed determining the residual stresses. However, due to the highly complex nature of welding involving various thermal, metallurgical and mechanical phenomena, uncertainties still remain in the accurate prediction and measurement of residual stresses. It is, therefore, reasonable to apply both of these methods in combination with each other to determine residual stresses and distortions. Increasing use of numerical simulation of welding in recent years using the finite element method has allowed a more resource efficient way of estimating transient thermal stress, residual stresses and distortions in comparison to experimental methods. However, 
predictions from weld modelling still require calibrations based on precise experimental measurement of welding thermal cycle, and constitutive behaviour of the weld metal, heat affected zone and base metal [17]. The transient temperature history during the welding process was calibrated by means of the measured thermocouple profiles and the fusion boundary of the weld seam was calibrated by the transverse cross-sectional micrograph of the welded specimens. Both X-ray and neutron diffraction measurement techniques were used in this work to determine the surface and through-thickness distribution of welding-induced residual stresses and then compared with the predicted results. It was, therefore, possible to understand the welding process and perform parametric studies to identify optimal welding parameters and control residual stresses and distortions in order to minimise the use of post weld stress relieving procedures. It is much easier to produce structures without distortion than to reduce it after welding through post-weld mechanical stretching [16]. 


\section{Material}

The material used in this work was aluminium alloy 2024-T3 in the form of thin sheets with a thickness of $3 \mathrm{~mm}$, a length of $500 \mathrm{~mm}$ and a width of $400 \mathrm{~mm}$. The filler metal was a 0.6 mm diameter consumable 4043 aluminium alloy. The chemical compositions of these two materials are listed in Table 1.

Table 1 Chemical composition of AA 2024-T3 and AA 4043 (Wt. \%)

\begin{tabular}{ccccccc}
\hline Material & Al & Cu & Mg & Mn & Cr & Si \\
\hline AA 2024-T3 & 92.1 & 5.9 & 1.0 & 0.6 & 0.1 & 0.3 \\
AA 4043 & 94.8 & - & - & - & - & 5.2 \\
\hline
\end{tabular}

Temperature-dependent thermophysical and thermomechanical material properties of AA 2024-T3 and AA 4043 were used in this investigation as illustrated in Figure 1 and Figure 2. An annealing temperature of $413^{\circ} \mathrm{C}$, solidus temperature of $502^{\circ} \mathrm{C}$ and liquidus temperature of $638^{\circ} \mathrm{C}$ were used. The temperature dependent tensile properties of AA 2024-T3 were obtained by tensile testing at a range of temperatures between $20^{\circ} \mathrm{C}$ and $500^{\circ} \mathrm{C}$ in a homogenised condition using the Gleeble 3800 thermo-mechanical simulator. The ratio of the gauge length $(25 \mathrm{~mm})$ to the gauge width $(5 \mathrm{~mm})$ was $5: 1$, complying with the standards. The specimen was clamped within copper grips and a pair of thermocouples was welded to each specimen to monitor the temperature within the gauge length and a C-gauge transducer was used to measure the change in the width of the specimen at its centre to calculate the strain under a constant volume assumption. A constant strain rate of $0.001 \mathrm{~s}^{-1}$ was used. Literature values for the temperature dependent tensile properties of AA 4043 as determined by Saad et al. [18] were used.

(a)

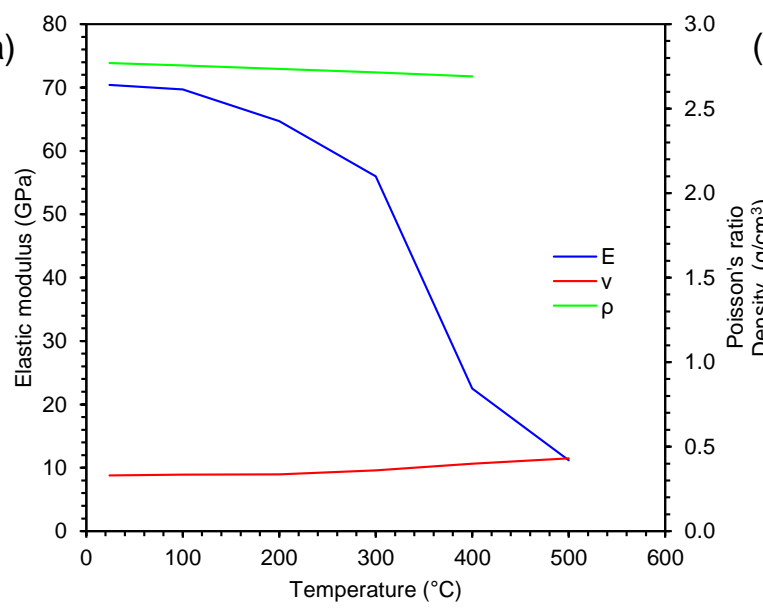

(b)

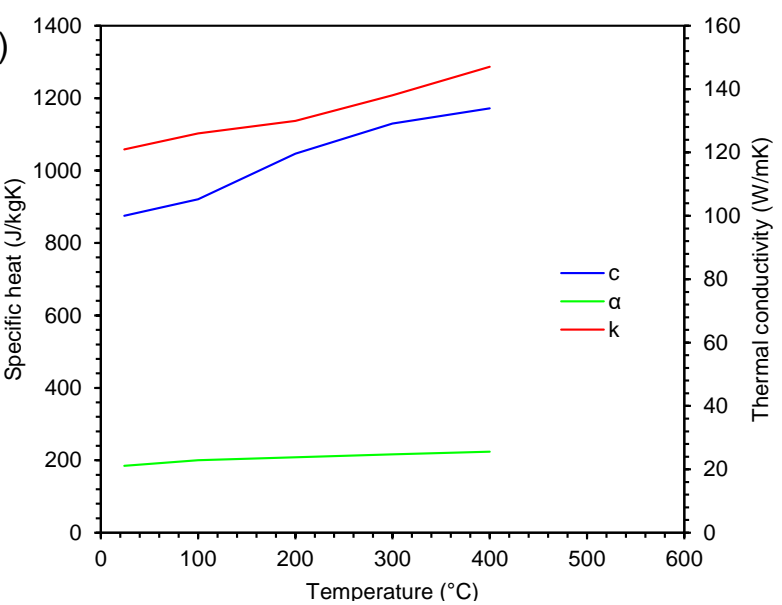

Figure 1 Temperature dependent thermophysical material properties of AA 2024-T3 used in the finite element model including the (a) elastic modulus, density, Poisson's ratio, (b) specific heat capacity, thermal diffusivity and thermal conductivity 

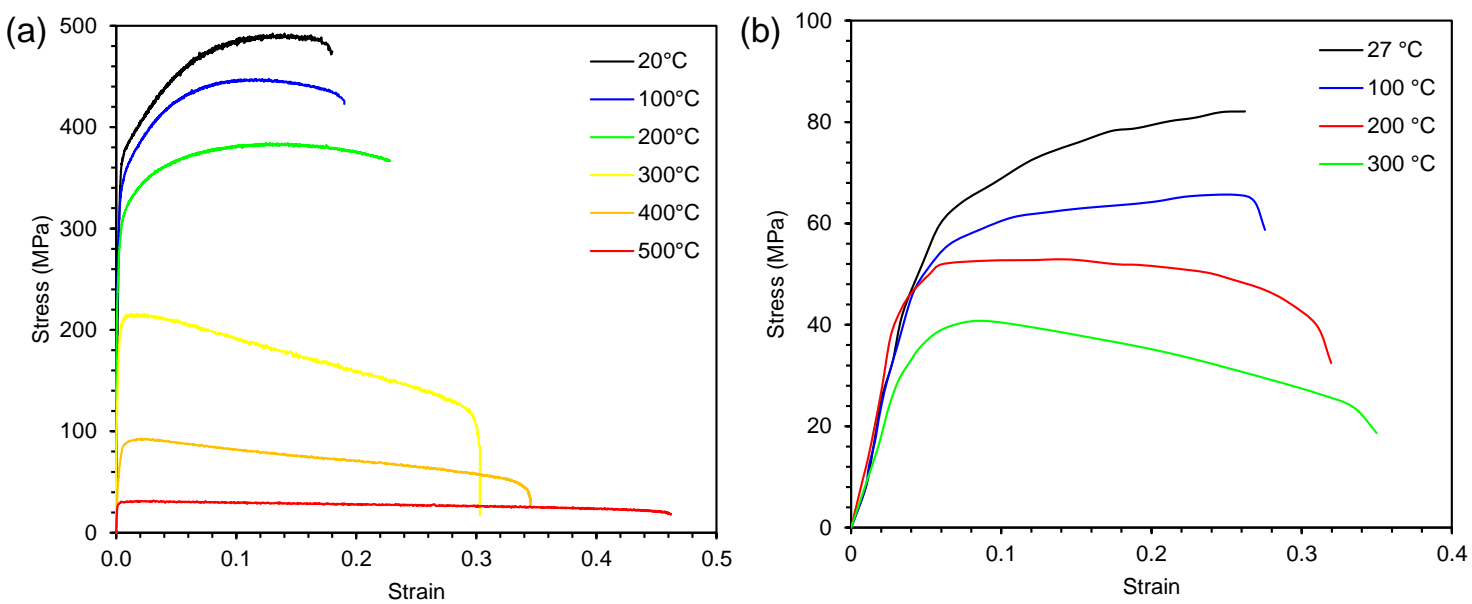

Figure 2 Temperature dependent thermo-mechanical material properties of (a) AA 2024-T3 and (b) AA 4043 used in the finite element model

\subsection{Welding condition}

A $5 \mathrm{~kW}$ IPG YLS-5000 multi-mode fibre laser was used to butt weld the AA 2024-T3 sheets. The properties of the fibre laser include $1.07 \mu \mathrm{m}$ wavelength, $\mathrm{M}^{2}$ of around 7 , divergence half angle of $12.5 \mathrm{mrad}$, Rayleigh length of around $3.1 \mathrm{~mm}$. The focal length of the focusing lens and the collimator lens was $300 \mathrm{~mm}$ and $100 \mathrm{~mm}$, respectively, while, the diameter of both was $50 \mathrm{~mm}$. The beam parameter product less than $2.5 \mathrm{~mm}$ mrad was achieved [19].

An independent investigation was conducted to optimize the welding parameters such as laser power, welding speed, beam focal position, filler wire feed rate and shielding gas type and the following three sets of welding conditions were chosen for welding trials as shown in Table 2 [4-7].

Table 2 Welding conditions

\begin{tabular}{ccccc}
\hline Weld ID & $\begin{array}{c}\text { Laser power } \\
(\mathbf{k W})\end{array}$ & $\begin{array}{c}\text { Welding speed } \\
(\mathbf{m} / \mathbf{m i n})\end{array}$ & $\begin{array}{c}\text { Focal position } \\
(\mathbf{m m})\end{array}$ & $\begin{array}{c}\text { Wire feed rate } \\
(\mathbf{m} / \mathbf{m i n})\end{array}$ \\
\hline Model A & 4.9 & 3.0 & +4 & - \\
Model B & 2.9 & 1.5 & +4 & - \\
Model C & 4.9 & 3.0 & +4 & 5.2 \\
\hline
\end{tabular}

\subsection{Temperature field measurement}

The welding thermal history was logged at $200 \mathrm{~Hz}$ by spot welding thermocouples at different positions on the welded sheets to the calibrate the heat source model and thermal boundary conditions of the FE models. As it was found to be difficult to precisely monitor the temperature history within the $\mathrm{FZ}$ or on the weld centre line due to an insufficient maximum operating temperature of the thermocouples used, measurements were taken adjacent to the weld centreline. 


\subsection{Residual stress measurement}

X-ray and neutron diffraction techniques were used to measure the welding residual stress at the locations shown in Figure 3.

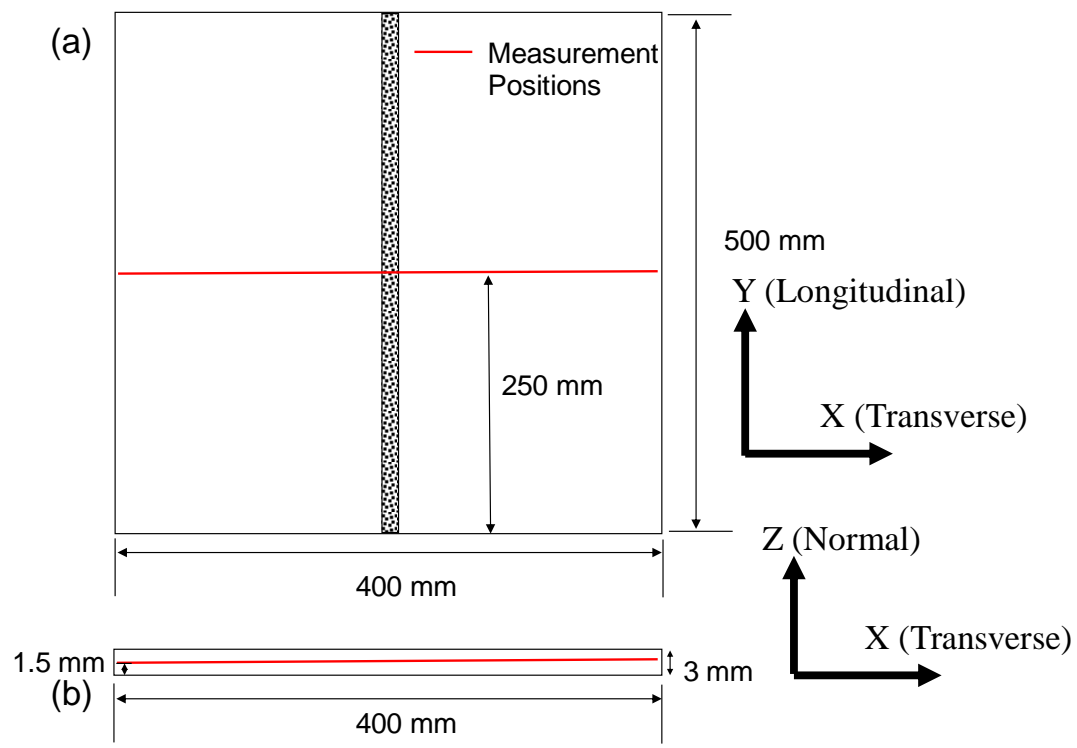

Figure 3 Residual stress measurement positions on the (a) top surface and (b) side

Strain measurements using an X-ray diffractometer was conducted at $20 \mathrm{kV}$ and $4 \mathrm{~mA}$. The in-plane surface strains were measured at a depth of $30 \mu \mathrm{m}$. Also, strains at mid-thickness of the sheets were measured using the neutron diffraction technique. The ENGIN-X neutron diffractometer at ISIS was used to measure two butt-welded AA 2024-T3 specimens. A gauge volume of $2 \times 2 \times 2 \mathrm{~mm}^{3}$ was used to measure the longitudinal strains parallel to the welding direction and $2 \times 20 \times 2 \mathrm{~mm}^{3}$ in the transverse and normal directions. Stress-free parameters were measured also using a gauge volume of $2 \times 2 \times 2 \mathrm{~mm}^{3}$ under identical conditions at every $2 \mathrm{~mm}$ interval from the weld centreline. The strains were determined by Rietveld refinement as a function of $\mathrm{X}$ distance from the weld centreline. The remaining specimen was measured using the E3 neutron diffractometer at HZB. A gauge volume of $2 \times 1 \times 2 \mathrm{~mm}^{3}$ was used to measure the longitudinal strains parallel to the welding direction, whereas, a $2 \times 19.3$ $\times 2 \mathrm{~mm}^{3}$ matchstick shape gauge volume in the other two directions. The elastic strain response of both $\{222\}$ and $\{311\}$ reflections were measured.

The change in lattice spacing was calculated using Bragg's Law as shown in Equation 1 by measuring the scattering angle, $2 \theta$ with the instrument.

$$
2 d_{h k l} \theta_{h k l}=\lambda
$$


where $\lambda$ is the wavelength of the radiation, $d_{h k l}$ is the lattice plane spacing and $\theta_{h k l}$ is the Bragg angle for a given crystallographic plane, denoted using Miller indices $\{\mathrm{hkl}\}$. Elastic strains were determined using the stress-free lattice spacing, $d_{0}$ and the corresponding diffraction angle, $\theta_{0}$. The elastic strain was calculated using Equation 2. The determined strain is an average elastic lattice strain over a sampled gauge volume defined by slits and formed by the intersection of the incident and diffracted beams [19].

$$
\varepsilon_{h k l}=\frac{d_{h k l}-d_{0, h k l}}{d_{0, h k l}}=\frac{\sin \theta_{0, h k l}}{\sin \theta_{h k l}}-1=\frac{t_{h k l}-t_{h k l}^{0}}{t_{h k l}^{0}}
$$

where $t_{h k l}$ and $t_{h k l o}$ are the measured and reference time of flight for the hkl peak, respectively.

The orthogonal stresses were calculated from the linear elastic properties of the material and the measured residual elastic strain in the relevant directions as shown in Equation 3 [19].

$$
\sigma_{i}=\frac{E_{h k l}}{\left(1+v_{h k l}\right)\left(1-2 v_{h k l}\right)}\left[\left(1-v_{h k l}\right) \varepsilon_{i}^{h k l}+v_{h k l}\left(\varepsilon_{j}^{h k l}+\varepsilon_{k}^{h k l}\right)\right] \quad \text { Equation (3) }
$$

where $E_{h k l}$ and $v_{h k l}$ are the elastic modulus and Poisson's ratio, respectively of a specific crystallographic plane. In the case where the Rietveld technique was used to fit an average lattice spacing to the whole diffraction pattern, the stress was calculated using the macroscopic bulk elastic constants.

A plane stress condition was assumed where the normal stress component was assumed to be zero $\left(\sigma_{z}=0\right)$ since the specimens were relatively thin such that $d_{0}$ was calculated for each point using the following relationship:

$$
\begin{gathered}
\sigma_{x}=\frac{E_{h k l}}{\left(1-v_{h k l}^{2}\right)}\left[\varepsilon_{x}^{h k l}+v_{h k l} \varepsilon_{y}^{h k l}\right] \\
\sigma_{y}=\frac{E_{h k l}}{\left(1-v_{h k l}^{2}\right)}\left[\varepsilon_{y}^{h k l}+v_{h k l} \varepsilon_{x}^{h k l}\right] \\
\sigma_{33}=0
\end{gathered}
$$

The $\sin ^{2} \Psi$ principle was applied to calculate the strain variation between two known principal axes perpendicular to the third principal axis.

\subsection{Distortion measurement}

Out of plane displacements in the welded sheet were measured using Nikon LK G-90C 
coordinate measuring machine (CMM). CMM is a high precision instrument for measuring the physical geometrical characteristics such as a surface contour of an object. A motorised automated probe head with an electronic touch trigger probe (TP200) mounted on a movable arm, which was connected to a micro-computer, was programmed to collect a series of point measurements along three lines in both longitudinal and transverse directions to the weld centreline with $10 \mathrm{~mm}$ spacing between points, by quickly pecking the surface over the entire specimen and providing an electrical signal when contact is made. By accurately detecting the $\mathrm{X}, \mathrm{Y}$ and $\mathrm{Z}$ coordinates of the object, points were generated and then analysed via regression algorithm for calculating the best-fitting line which minimises the sum of the squared vertical distances from the data points to the line [20].

\subsection{Digital Image Correlation}

Digital image correlation (DIC) technique was used to characterise the local and global constitutive properties of the weld and the parent material. The experimental setup included a single CCD camera positioned perpendicular to object surface and uniformly illuminated by white light sources. A random black and white speckle pattern were applied on the surface of the tensile specimen which was loaded nominally in-plane. Small square facets were initially assigned to the undeformed image and then matched to locations after deformation in order to obtain full-field displacement data. All tensile tests were conducted in combination with a local strain field analysis using the ARAMIS 2D DIC 5M optical deformation analysis system developed GOM GmbH. Local stress data were obtained from the globally applied load, assuming an iso-stress condition and that stress triaxiality does not influence the mechanical behaviour. Local strain data were obtained from the ARAMIS software for any position within the displacement field. The global stress data were combined with the local strain data to determine the local mechanical properties of the different weld regions. 


\section{$3 \quad$ Finite element modelling}

Experimental measurement of welding temperature fields, residual stresses and distortions are time-consuming, expensive and there may also be uncertainties associated with the measurements [21]. Thus, computational welding simulation is often used to predict the distribution and magnitude of transient residual stress fields and distortions in different types of materials and joints during and after welding. The advantage of welding simulation is that calculations are cheaper and faster than conducting experiments. It allows retrieving quantities which are difficult to measure experimentally and investigate systematically the influence of various aspects of welding such as welding parameters, restraints and subsequent processing by simulating ideal conditions which eliminate the practical limitations of conducting experimental studies for process optimisation [22]. However, computational simulation still requires experimental calibration on measurable parameters such as the weld pool geometry and temperature field to determine net heat input. It was important to validate the model experimentally before using it to conduct parametric studies.

A three dimensional thermal elastic-plastic finite element model was developed using the commercial code ABAQUS/Standard to calculate welding temperature fields, residual stresses and deformations of butt-welded sheets. The thermomechanical behaviour of the weldment was simulated using a two-step uncoupled analysis as the dimensional changes and the amount of heat generated due to mechanical work done during welding was assumed to be negligible compared to the total thermal energy supplied from the welding heat source. In the first step, a thermal analysis was conducted where temperature distributions of all nodes during and after welding were obtained using a heat conduction analysis and in the second step, a mechanical analysis was conducted to calculate the residual stresses and distortion by applying the transient temperature field history from the first step as predefined thermal body loads.

For accurate predictions, high-quality temperature field and material constitutive data and appropriate boundary conditions were required. It was also important to include the effect microstructure evolution due to softening in AA 2024-T3, which may lead to changes in the peak residual stress values. During the whole welding process, both thermal and mechanical properties of the weld, heat affected zone and parent material were temperature dependent.

Due to the nature of the welding process, a $2 \mathrm{D}$ model was not adequate for many practical 
problems so a full-scale 3D model consisting of finite solid elements with time incremental representation of the moving heat source was necessary. It was also possible to predict out-ofplane deformations in all geometrical directions like angular distortion and cambering that cannot be obtained from the $2 \mathrm{D}$ analysis.

Table 3 shows the details about the mesh for different welded components including the number of nodes and elements, element type used for thermal and mechanical analyses. The same finite element mesh was used for both the thermal and mechanical analysis.

Table 3 Mesh details for butt welded and T-joint fillet welded plates

\begin{tabular}{cccccc}
\hline & Thermal & & \multicolumn{3}{c}{ Mechanical } \\
\hline Nodes & Elements & Type & Nodes & Elements & Type \\
\hline 527693 & 115800 & DC3D20 & 137410 & 115800 & C3D8R \\
\hline
\end{tabular}

In the thermal analysis, $2^{\text {nd }}$ order 3D 20 node quadratic diffusive heat transfer brick hexahedron elements (DC3D20) were used, whereas, in the mechanical analysis, $1^{\text {st }}$ order 3D 8 nodes linear hexahedron reduced integration elements (C3D8R) were used. To transfer the nodal temperature data from the thermal results file that was generated during the thermal analysis to the mechanical model for the mechanical analysis, the same finite element mesh was used, with the same number of elements but different element types. Figure 4 shows mesh refinement for different element sizes, either 1-2 or 3-5 mesh transition. At least three to four stages of mesh refinement were used by partitioning and transforming the mesh to create a user controlled refined mesh so that the computation time can be minimised and still be able to achieve accurate results, especially near the welding region. Convergence studies on mesh density were done prior to this investigation [23] to ensure that a sufficiently refined mesh is used to yield accurate simulation results and to examine the solution's sensitivity to element type and boundary conditions, the details of which are shown in Table $\mathbf{3}$, where the smallest element size was $0.5 \times 0.5 \times 0.5 \mathrm{~mm}^{3}$. The mesh converged when further mesh refinement produced a negligible change in the solution. It was found that a model with 115,800 elements for butt welds was sufficient to accurately represent stress values in the weld region. A very fine mesh density was required in the weld region due to the small diameter of the moving heat source which traverses along the weld at specific time steps and the resulting high temperature and stress gradients in the fusion zone and the heat affected zones. The element size increased progressively with increasing distance from the weld centreline. At least three to four stages of mesh refinement were used by partitioning and transforming the mesh to create a user controlled refined mesh so that the computation time 
can be minimised and still can achieve accurate results.

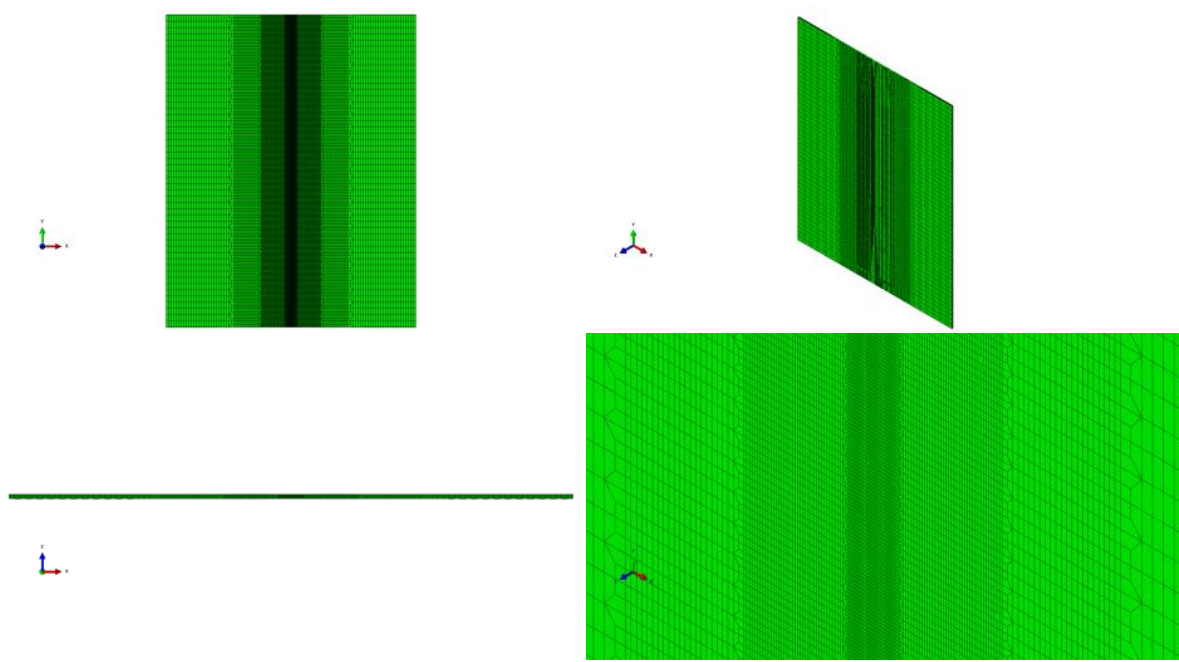

Figure 4 Finite element model mesh details of a butt-welded sheet with a user-controlled refined mesh

\subsection{Thermal analysis}

The laser welding heat was applied as a user-defined heat flux which had a 3D conical Gaussian power density distribution radially and a linear distribution axially programmed in ABAQUS via the user-defined subroutine DFLUX. This heat source model produces most accurate results for deep penetration laser beam welding in a thermal analysis. A model developed by Ahn et al. [19] was used in this analysis and the equations are given below. The heat source model considers the start point of heat input as well as current coordinates of the Gaussian point. It has the maximum heat flux on the top surface and the minimum on the bottom surface as expressed in Equation 7.

$$
q_{r}(r, z)=q_{0} e^{-3\left(\frac{r}{r_{0}}\right)^{2}}
$$

where $r_{0}$ is the radius of the heat source at a specific height $z, q_{0}$ is the maximum volumetric power density and $r$ is the current radius of the interior point, which according to Equation 8 is:

$$
r=\left[\left(x-x_{0}\right)^{2}+\left(y-y_{0}-v t\right)^{2}\right]^{\frac{1}{2}}
$$

The current radius takes into account the welding speed and also time so the non-symmetric heat flux distribution of a moving laser beam can, therefore, be realised. The distribution parameter, $r_{0}$, decreases linearly from the top to the bottom of the conic region as shown in 
Equation 9.

$$
r_{0}(z)=r_{e}-\left(r_{e}-r_{i}\right) \frac{\left(z_{e}-z\right)}{z_{e}-z_{i}}
$$

where $z_{\mathrm{e}}$ is the top surface and $z_{i}$ is the bottom surface of the cone region. The maximum volumetric power density can be obtained by integrating the volumetric heat flux, $Q$ over the body and rearranging it to the total heat input as shown in Equation 10.

$$
\begin{aligned}
& Q=\int_{0}^{H} \int_{0}^{2 \pi} \int_{0}^{r_{0}} q_{0} e^{-\frac{3 r^{2}}{r_{0}^{2}}} r d r d \theta d h \\
& q_{0}=\frac{9 \eta Q e^{3}}{\pi\left(e^{3}-1\right)\left(z_{e}-z_{i}\right)\left(r_{e}^{2}+r_{e} r_{i}+r_{i}^{2}\right)}
\end{aligned}
$$

where $H=z_{e}-z_{i}$ and $h=z-z_{i}, e$ is the base of the natural logarithm and $\eta$ is the heat source efficiency. Heat source efficiency or energy transfer efficiency is defined as the ratio of the energy absorbed by the irradiated materials to the laser power output. The energy transfer efficiency used in the thermal model simulation was in the range of $75 \%$ after calibration with experimental thermocouple measurement of welding transient temperatures. The value was established by matching the thermal analysis results to experimental measurement of welding thermal histories. Several iterations were made to fit the heating and cooling rate, start and end temperatures and the maximum temperature reached. The process first involved matching the simulated weld transverse cross-section profile to experimental macrographs by changing the thermal efficiency value and heat source distribution parameters. Secondly, the welding thermal cycle was calibrated by changing the values for the ambient temperature; and conductive, radiative and convective heat loss using the *RADIATION and *FILM options in ABAQUS. The cooling rate was largely sensitive to the heat conduction parameters.

The heat source was simulated using DFLUX by prescribing a user-defined volumetric heat flux input to the weld model. The heat equation derived from Fourier's law and conservation of energy as shown in Equation 11 was used to solve the transient temperature field $(T)$ in time $(t)$ and space $(x, y, z)$ : 


$$
\rho C_{p} \frac{\partial T}{\partial t}=\frac{\partial}{\partial x}\left(k \frac{\partial T}{\partial x}\right)+\frac{\partial}{\partial y}\left(k \frac{\partial T}{\partial y}\right)+\frac{\partial}{\partial z}\left(k \frac{\partial T}{\partial z}\right)+\dot{Q}_{V} \mathrm{E}
$$

where $T$ is the temperature, $\rho$ is the density, $C_{p}$ is the specific heat, $k$ is the thermal conductivity and $\dot{Q}_{V}$ is the volumetric heat flux in $\mathrm{W} / \mathrm{m}^{3}$. To solve the heat equation, the thermal conductivity, density and specific heat must be specified.

The initial and ambient temperature of the $\mathrm{FE}$ model was set to $20^{\circ} \mathrm{C}$. Thermal boundary conditions consider the heat transfer due to convection in the air, radiation from the surface of the workpiece to ambient air and conduction from the workpiece to the mild steel support as shown in Figure 5. A trial and error method was used to calibrate the heat transfer coefficients to match the logged temperature fields.

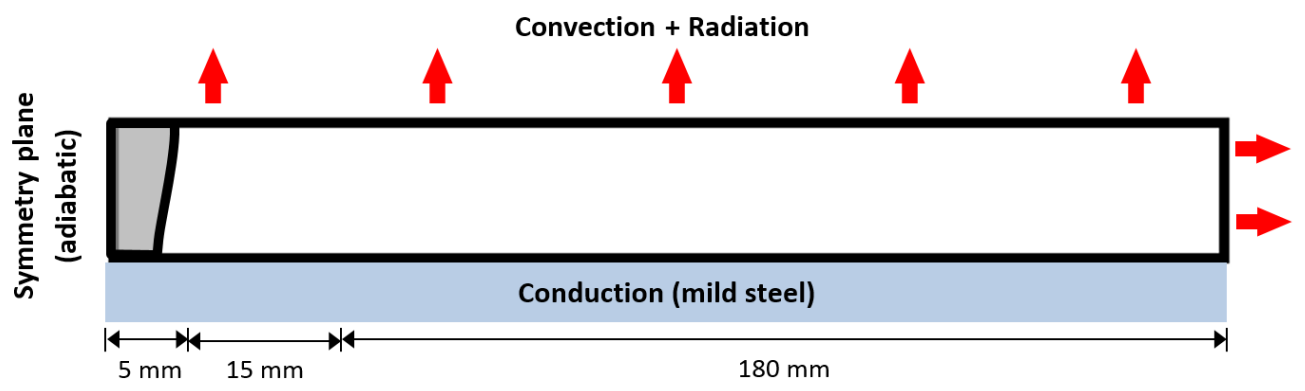

Figure 5 Illustration of the thermal boundary conditions

Equation 12 and Equation 13 define heat loss due to surface convection and radiation, respectively, as boundary conditions.

$$
\begin{gathered}
q_{c o n v}=h_{c o n v}\left(T-T_{0}\right) \\
q_{r a d}=\varepsilon \sigma\left[\left(T-T_{a b s}\right)^{4}-\left(T_{0}-T_{a b s}\right)^{4}\right]
\end{gathered}
$$

where $T$ is the current temperature, $T_{0}$ is the ambient temperature, $T_{a b s}$ is the absolute zero temperature, $\varepsilon$ is the emissivity or the ability to emit thermal radiation and $\sigma$ is the StefanBoltzmann constant $\left(5.68 \times 10^{-8} \mathrm{~J} / \mathrm{K}^{4} \mathrm{~m}^{2} \mathrm{~s}\right)$. The effect of radiation is greater at higher temperatures (close to the weld) and insignificant at low temperatures (far from the weld). The calibrated values used for the heat transfer coefficients and radiation constants are listed in Table 4.

Table 4 Calibrated values for heat transfer coefficients and radiation constants

\begin{tabular}{cc}
\hline $\mathbf{h}(\mathbf{W} / \mathbf{K m})$ & $\varepsilon$ \\
\hline 5 & 0.05 \\
\hline
\end{tabular}




\subsection{Mechanical analysis}

Mechanical response of the material was calculated using infinitesimal strain theory as shown in Equation 14 assuming elastic-plastic behaviour with isotropic hardening law (von Mises rate independent deviatoric plasticity model).

$$
\varepsilon_{i j}^{T o t a l}=\varepsilon_{i j}^{e}+\varepsilon_{i j}^{p}+\varepsilon_{i j}^{t h}+\varepsilon_{i j}^{c}+\varepsilon_{i j}^{v p}+\varepsilon_{i j}^{t p}
$$

where $\varepsilon_{i j}^{\text {Total }}$ is the total strain, $\varepsilon_{i j}^{e}$ is the elastic strain, $\varepsilon_{i j}^{p}$ is the plastic strain, $\varepsilon_{i j}^{t h}$ is the thermal strain, $\varepsilon_{i j}^{c}$ is the creep strain, $\varepsilon_{i j}^{v p}$ is the viscoplastic strain and $\varepsilon_{i j}^{t p}$ is the transformation plasticity strain. The total strain was composed of the above strain components. It was assumed that the strain caused by creep, viscoplasticity and trip components are negligible and therefore, not included in the calculations. Since the viscoplastic effects were ignored, the yield stress was assumed to be independent of the strain rate and dependent upon plastic strain and temperature.

As low yield strength at high temperatures causes large plastic strains to develop and cause artificial hardening and higher stress values, an annealing temperature was included by setting the equivalent plastic strain to zero above the specified annealing temperature so that the effect of prior hardening is lost. If the temperature at a material point falls below the annealing temperature, then it can work-harden. By including the annealing effect, the residual stresses in the weld region could be reduced significantly. In addition, softening of the weld was modelled to accurately simulate the resulting welding residual stress field. It was done by using the weld constitutive data as field variables in place of the parent metal data during the cooling stage. Transition zones of intermediate mechanical properties between those of the parent metal and the weld were introduced as well to avoid non-gradual variations of mechanical properties in the weld region. The addition of filler metal during welding was simulated using model change (element death and rebirth), where the relevant elements were assigned the same weld material properties and initially inactivated but they became activated as soon as the corresponding part of the weld was simulated.

Mechanical boundary conditions were prescribed to fix the workpiece while it is being welded. Three different clamping conditions were considered as shown in Figure 6 to investigate the effects of different clamping conditions on welding residual stresses and 
distortions with the aim to control and minimise both to produce high strength, low stresses and dimensionally stable welded structures. In the first case, the workpiece was welded without any restraint (free) except those to prevent rigid body motion as shown in Figure 6 (a). In the second case, the workpiece was completely fixed around all edges as shown in Figure 6 (b). In the last case, the boundary conditions were set to simulate the actual welding fixtures (clamp) with closer clamping to and larger restraints at the weld seam, used during welding experiments as shown in Figure 6 (c). It is a common practice to use fixtures to reduce welding distortions. However, distortion control is a difficult task because the welding fixtures strongly affect the residual stresses and distortions induced during welding due to the complexity of the welding process so they should be designed carefully.

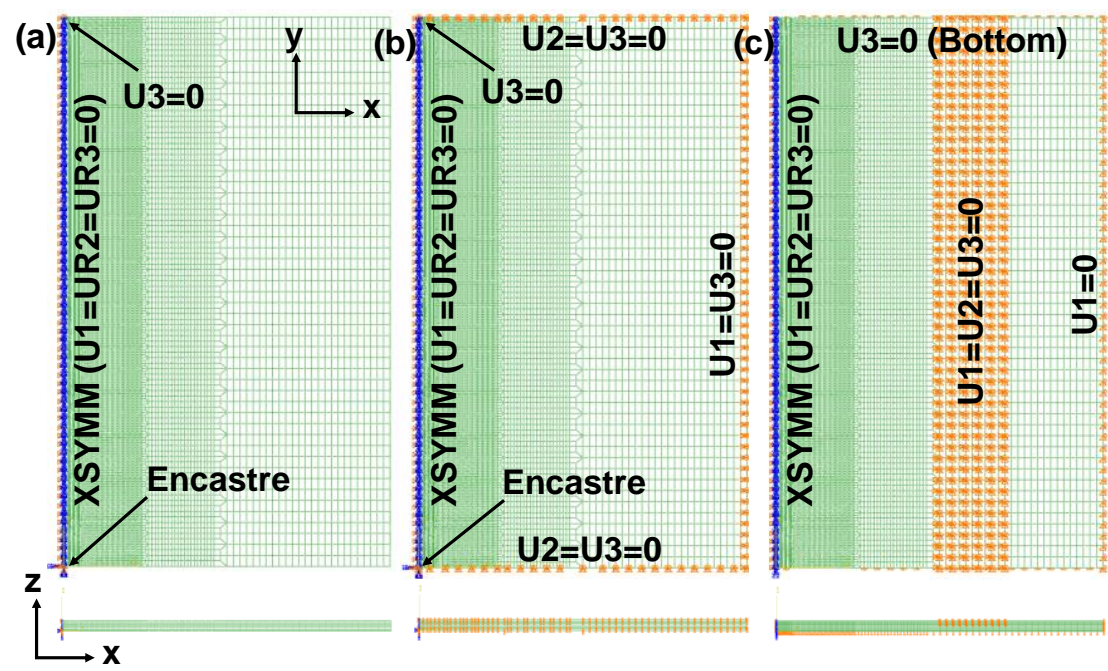

Figure 6 Mechanical boundary conditions applied during welding and cooling (a) free, (b) fixed around the edges and (c) clamping fixtures 


\section{Results and discussion}

\subsection{Validation of simulation models using experimental data}

The temperature distributions during welding the AA 2024-T3 sheets are shown in Figure 7 (a). The temperature gradient is very steep and confined to a narrow region around the heat source at the location of keyhole formation reaching temperatures close to the boiling point of about $2500^{\circ} \mathrm{C}$, and elongated in the welding direction due to the high-power density and low heat input characteristics of the moving fibre laser heat source. The welding heat quickly dissipates behind the heat source towards the lower temperature outer edges of the specimens due to very fast welding speed and elevated thermal conductivity values of the material at higher temperatures. The regions in white which are above the melting point of $638^{\circ} \mathrm{C}$ completely penetrate through the thickness of butt welded sheets, indicating a full penetration mode welding.

The molten zone or the width of the fusion zone was determined by the temperature contour above the liquidus temperature of $638^{\circ} \mathrm{C}$ and the width of the heat affected zone was determined by the temperature contour between the liquidus and the solidus temperature of Figure 7 (a) shows the distribution of temperature gradient with increasing distance from the weld centre and Figure 7 b) illustrates the simulated fusion boundary isotherms compared to the weld seam macrographs.
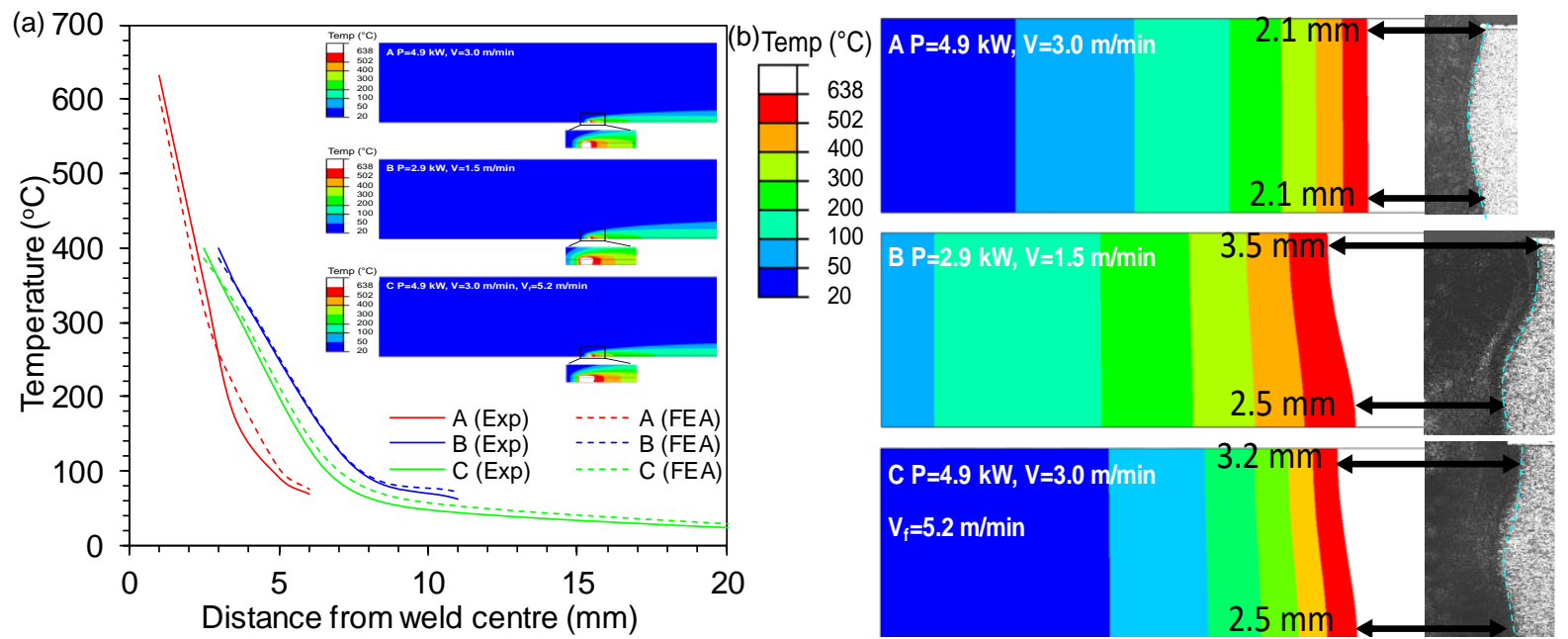

Figure 7 Temperature contours obtained from thermal analysis (a) halfway through butt welding AA 2024-T3 and (b) comparison of butt weld transverse cross-section geometry through thickness between FE model and experimental macrograph juxtaposed under three different welding conditions

The experimentally measured weld seams had the top and bottom widths as shown in Table 5 . Small reinforcement and excessive penetration as observed in the actual macrograph were not modelled as they were assumed to have negligible influence on residual stresses and distortions. Table 5 also shows the calibrated heat source parameters $r_{e}$ and $r_{i}$ used in the 
DFLUX subroutine for different welding conditions and weld geometries, and the heat source efficiencies were determined to be in the range between 70 and $80 \%$.

Table 5 Calibrated heat source parameters for welding AA 2024-T3 under various welding conditions

\begin{tabular}{ccccc}
\hline Weld ID & Top weld width & Bottom weld width & $\begin{array}{c}\boldsymbol{r}_{\boldsymbol{e}} \\
(\mathbf{m m})\end{array}$ & $\begin{array}{c}\boldsymbol{r}_{\boldsymbol{i}} \\
(\mathbf{m m})\end{array}$ \\
\hline Model A & 2.1 & 2.1 & 0.1495 & 0.1485 \\
Model B & 3.5 & 2.5 & 0.1905 & 0.1270 \\
Model C & 3.2 & 2.5 & 0.1750 & 0.1395 \\
\hline
\end{tabular}

An additional calibration step involved matching the simulated curves to the temperature history recorded at various thermocouple positions by changing the thermal boundary conditions such as thermal convection and radiation to the surroundings and conduction to the worktop. Figure 8 shows that the experimental and simulated time-temperature curves at several locations match well in terms of heating rate, peak temperature and cooling rate. As the temperature reached significantly higher than the maximum operating temperature of the thermocouple in the FZ, the closest measurements were taken at some distance away from the weld centre line and the rest further away. The figure suggests that the heating and cooling speed are very fast during the welding process for all specimens, which was found to take less than a period of 5 seconds only from heating to the peak temperature to cooling to less than $50^{\circ} \mathrm{C}$. Since the specimens were all very thin, it was assumed that the temperature distribution through the thickness is almost uniform regardless of the distance from the welding centre line except within the weld seam. It was then decided that the thermal FE model experimentally validated through transient temperature and weld pool measurements became accurate enough to transfer the nodal temperature histories for mechanical analysis.
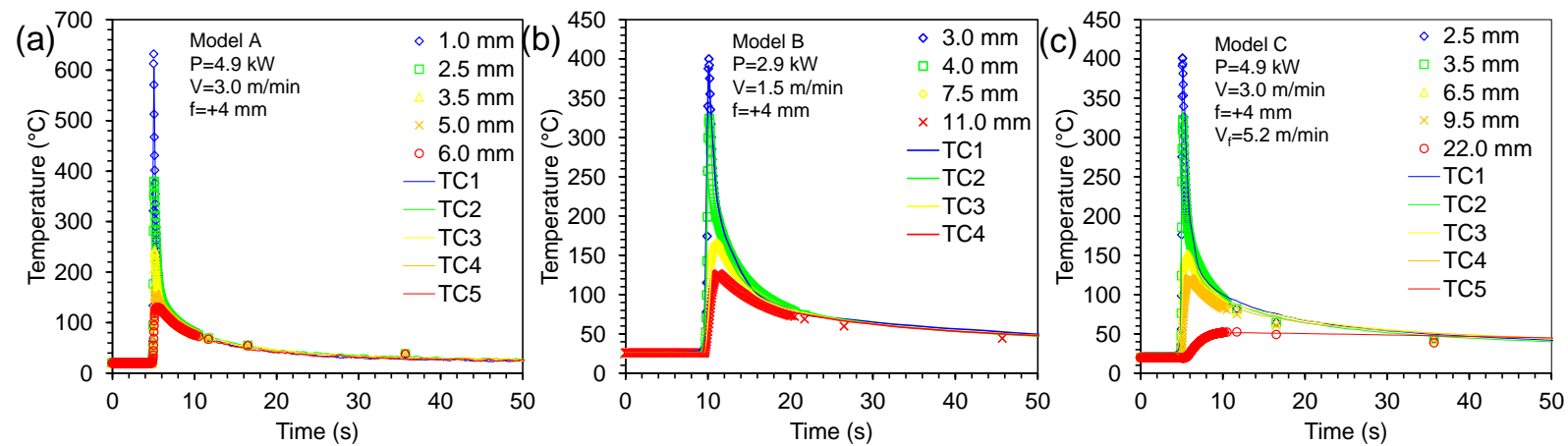

Figure 8 Simulated thermal histories calibrated using thermocouple measurements at various distances from the weld centre line for butt welded (a) Model A, (b) Model B and (c) Model C

Post weld heat treatment for thermal stress relieving is difficult and impractical for heat treatable aluminium alloys. A typical artificial ageing temperature is not sufficiently high enough to effectively achieve a significant reduction of the yield strength to obtain the 
desired stress relief. As the temperature increases, the yield strength falls, allowing the material to plastically deform by a creep mechanism until the residual stress level decreases to match the yield strength at the heat treatment temperature. On the other hand, temperatures which are greater than the ageing temperature and also high enough to relieve stresses, of around $232^{\circ} \mathrm{C}$ [24] cause further precipitation and over-ageing to occur and therefore, seriously reducing the strength level and increasing welding distortions. Welded structures which have been heat treated and aged to T3 temper prior to welding cannot be subsequently heated to the stress relieving temperatures.

\subsection{Influence of weld softening on residual stresses}

Non-uniform thermal expansion and contraction due to different temperature gradients during the heating and cooling sequence of welding process resulted in tensile and compressive residual stress fields in and near the weld region. Variations in the magnitude and distribution of residual stress fields due to welding were examined in this investigation, considering the different material properties including those of the parent metal, weld metal and filler metal, along with other parameters such as geometrical and welding process parameters.

The thermal strain was not sufficient to cause yield strength magnitude residual stresses due to high yield strength and low elastic modulus of AA 2024-T3. It was necessary to more accurately measure or develop validated FE models incorporating the softening effect in AA 2024-T3 welds to predict welding-induced residual stresses and distortions as close as possible to the real values. The softening effect was included in the FE models by considering the mechanical response of welds. Constitutive data for the various microstructural regions that make up the weld including the FZ and HAZ were determined via experimental measurements using digital image correlation (DIC) on welded tensile specimens. First, the parent material properties were used during the heating stage of the welding thermal cycle and then replaced by the weld constitutive behaviour during the cooling stage. Transition zones of intermediate mechanical properties between those of the parent metal and the weld were also introduced to avoid non-gradual variations of mechanical properties in the weld region.

Softening in AA204-T3 deteriorated the plastic straining capacity of the weld due to confined plasticity development within the weld. It was caused by high temperatures of the welding thermal cycle which induced dissolution of strengthening precipitates in the matrix. The 
heating action of the laser led to segregation of elements, formation and growth of nonstrengthening coarse precipitates, dissolution of strengthening precipitates and uniform distribution of precipitating elements during heating which then froze due to fast cooling rates. The hardening effect was therefore removed and the mechanical properties of the weld degraded.

Figure 9 shows the effect of modelling softening in the weld on the residual stress distributions. A highly localised narrow region of tensile longitudinal residual stresses around the weld (HAZ) of around $250 \mathrm{MPa}$ with lower tensile stress magnitude softened weld metal (FZ) of around $100 \mathrm{MPa}$ was found. The remaining far field regions showed almost no residual stresses or negligible compressive stresses. The contributions from transverse and normal stresses were relatively small.

(a)

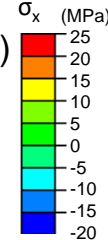

(b)

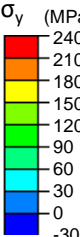

(C)

$\sigma_{\mathrm{z}} \quad(\mathrm{MPa})$

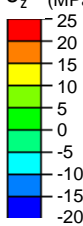

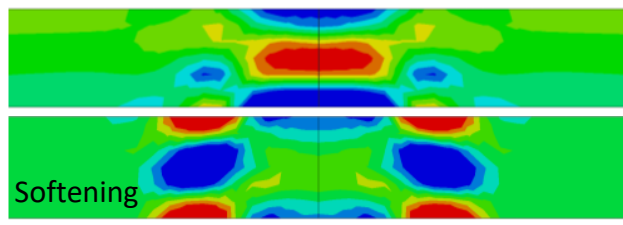
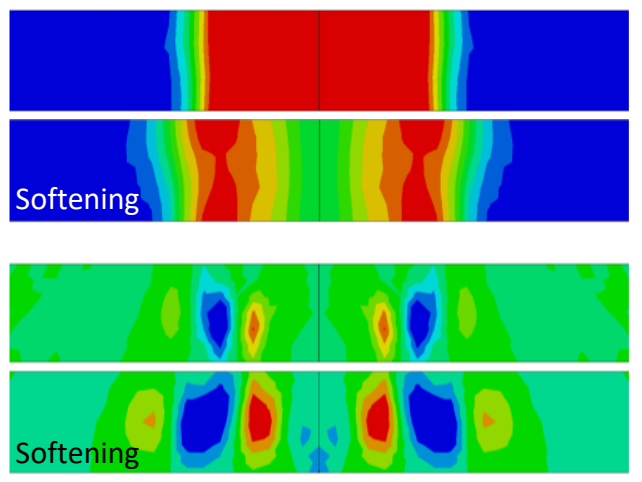

$\sigma_{\mathrm{x}}$
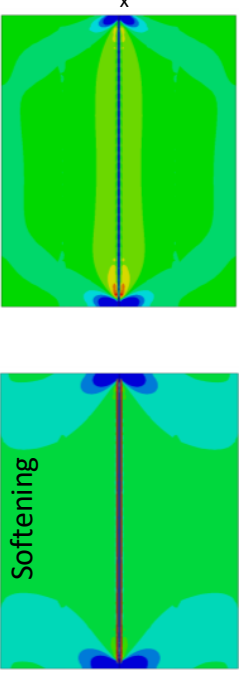

$\sigma_{z}$
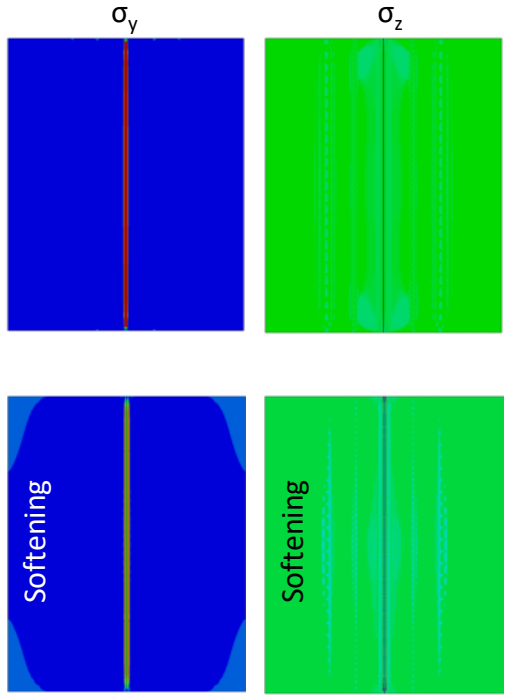

Figure 9 Contours of residual stress distribution on the weld transverse cross-section and top surface of butt welded joints in (a) $x$, (b) $y$ and (c) $\mathrm{z}$ directions through thickness with or without softening

Without softening, the entire weld region is in tension both in the transverse and longitudinal directions. The peak magnitude of the longitudinal stress of around $280 \mathrm{MPa}$ without softening is located at the specimen centre, spanning across both the FZ and the HAZ, whereas, there is a dip as mentioned above, in longitudinal stress at the specimen centre with softening as shown in Figure 10. The maximum difference in longitudinal stresses according to these two models is almost as high as $200 \mathrm{MPa}$. It seems too conservative to assume that yield magnitude residual stresses occur in AA 2024-T3 laser welds. Peak residual stresses as high as the yield strength are likely to occur only when the thermal contraction strain becomes larger than the yield strain. Therefore, erroneous results can be produced when the 
effect of softening is not considered and such difference can be clearly observed according to the neutron diffraction measurement results which closely follow the numerical results with the softening effect incorporated.
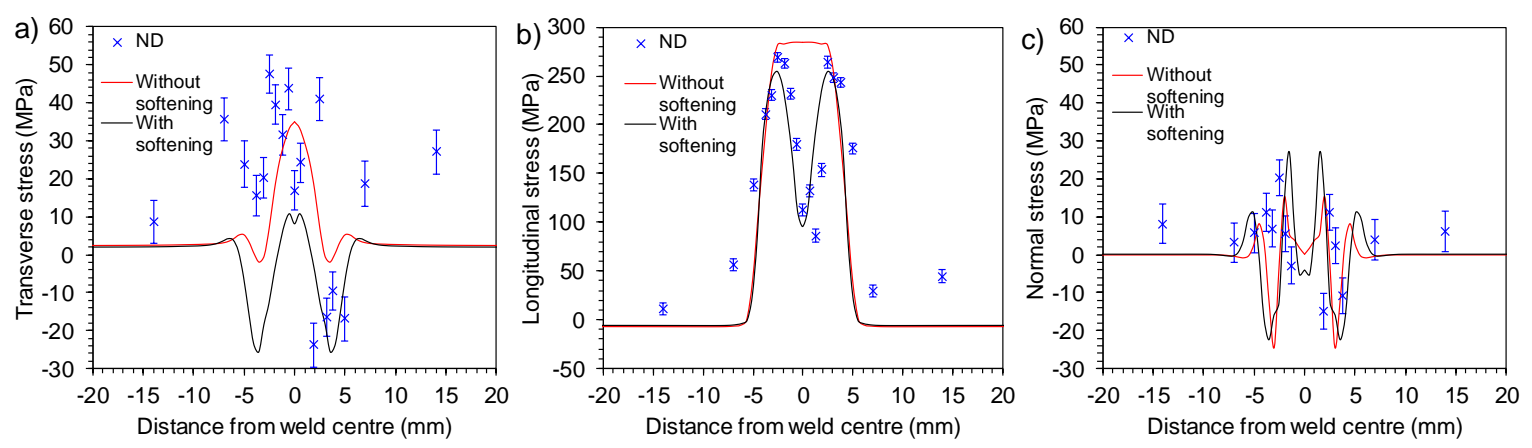

Figure 10 Residual stress distributions in (a) $x,(b) y$, and (c) $\mathrm{z}$ directions with or without softening

\subsection{Effects of different restraint on residual stresses and deformations}

The influence of mechanical boundary conditions on the welding-induced residual stress distributions and distortions are shown in Figure 11 and Figure 12. The predicted residual stresses are again symmetric across the weld centre line in and around the weld. Both the transverse and normal stresses are small compared to the longitudinal stresses across the width of the welded sheets, with peak magnitudes of less than $30 \mathrm{MPa}$ for all three cases. Low magnitude tensile stresses are observed in the weld and compressive stresses adjacent to the weld. These low magnitude stresses approach a zero value after a short distance away from the weld centre line. It appears that there is some variation in transverse stresses through the thickness where compressive stresses are observed on the top and bottom surfaces and tensile stresses at the interior. Similarly, tensile residual stresses are observed again on the top and bottom surfaces and compressive stresses at the interior adjacent to the weld. On the other hand, negligible variation in thickness was observed for longitudinal and normal stresses. 
(a)

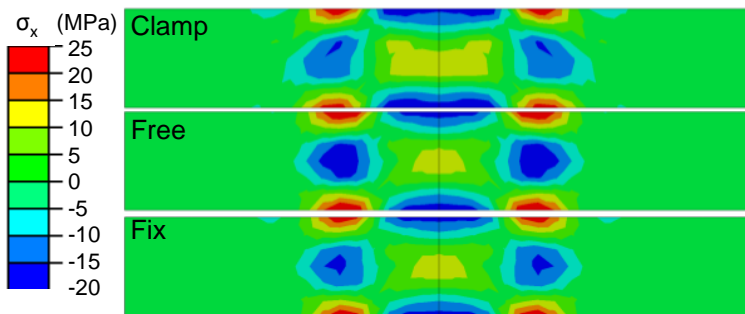

(b)
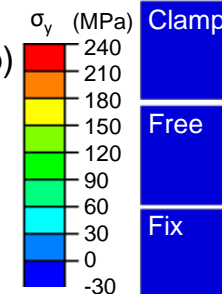$$
\text { Clamp }
$$

$\sigma_{\mathrm{z}} \quad(\mathrm{MPa})$ Clamp

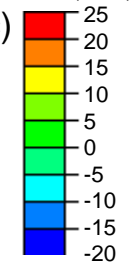

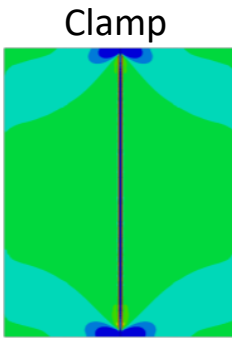
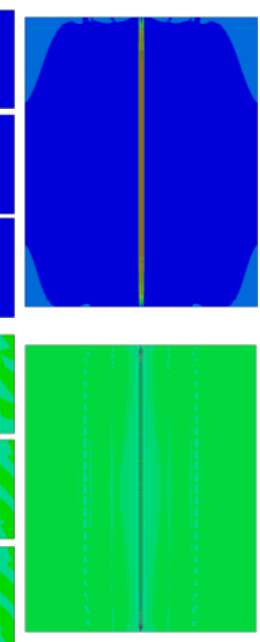

Fix
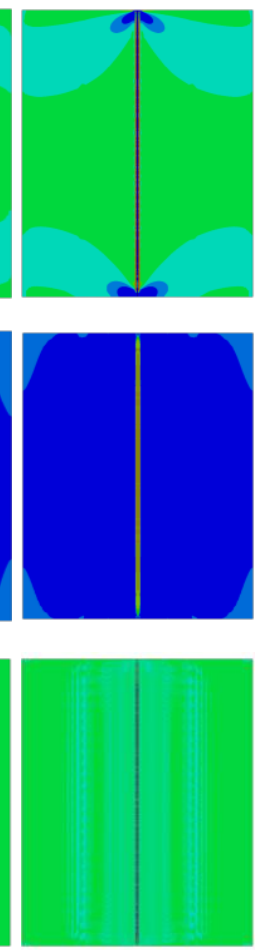

Free
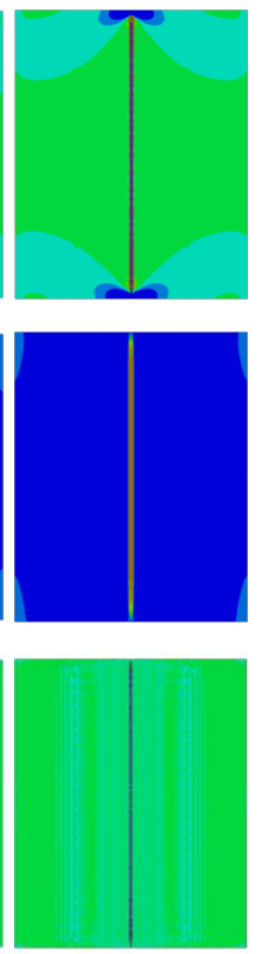

Figure 11 Contours of residual stress distribution on the weld transverse cross-section and top surface in (a) $\mathrm{x}$, (b) $\mathrm{y}$ and (c) $\mathrm{z}$ directions through thickness under different mechanical boundary conditions

Predominantly high magnitude tensile residual stress fields are observed in the longitudinal direction around the weld with the peak value in the FZ/HAZ boundary slightly lower than the yield strength of the parent metal at room temperature. The maximum longitudinal residual stress is not located at the weld centre line as expected, due to softening discussed previously. The tensile residual stresses around the weld quickly drop again and approach a zero value away from the weld which tends to be weakly compressive. As it can be seen from Figure 12, only a narrow region within approximately $5 \mathrm{~mm}$ around the weld are affected by the localised heating during the welding process due to the low heat input and high-power density characteristics of the fibre laser. Therefore, largely tensile residual stresses are observed very close to the weld and the stress level in the remaining regions are close to zero.

Although it was initially expected that weld joints with more restraint result in higher residual stresses, the results from Figure 12 indicate that it is not necessarily true in this case. No significant variation in residual stresses can be observed for different constraint sets examined after the removal of the restraints for all conditions. Instead, similar distributions and magnitudes are observed. Therefore, it can be concluded that residual stresses in thin sheets of fibre laser welded AA 2024-T3 is weakly sensitive to the chosen mechanical boundary conditions and the extent of variation shows no signs of different constraints in the 
reduction of residual stress fields. The experimentally determined stresses via neutron diffraction measurements and the corresponding numerical results for the clamped condition show a good agreement in terms of the peak magnitude and distribution of longitudinal stresses.
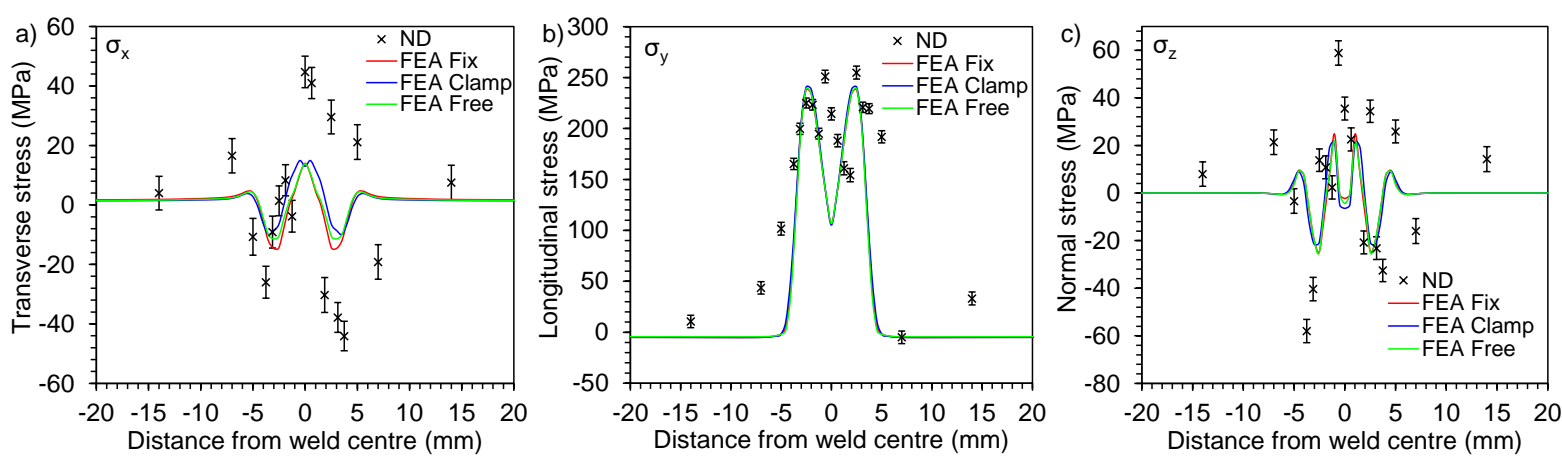

Figure 12 Residual stress distributions in (a) $x$, (b) $y$, and (c) $\mathrm{z}$ directions under different mechanical boundary conditions

It was found that fibre laser welding these sheets led to minimum welding distortions, typically less than a few millimetres, unlike significant welding distortions often observed with conventional welding processes which are often greater than $10 \mathrm{~mm}$ [23]. While it is difficult to differentiate from the stress contours in Figure 11, the minimal influence of mechanical boundary conditions on the residual stress distributions, its effect on the out of plane displacements is clear and had a major influence. Figure 13 shows that clamping close to the weld region to resemble the clamping fixtures used during welding trials leads to a slight reduction in compressive transverse and normal residual stresses in and around the weld but the effect is negligible. In addition, almost no difference can be found in longitudinal stresses with respect to mechanical boundary conditions. On the other hand, displacement contours in Figure 13 and displacement plots in Figure 14 show that welding distortion is closely related to the magnitude of residual stresses as well as the degree of joint restraint during the welding process. The correlation between distortion and mechanical boundary condition is such that higher restraint leads to lower distortion and vice versa. The least amount of out of plane displacement is achieved by using clamping fixtures located close to the weld region, followed by perfect restraints around outer edges and finally without any restraints. 

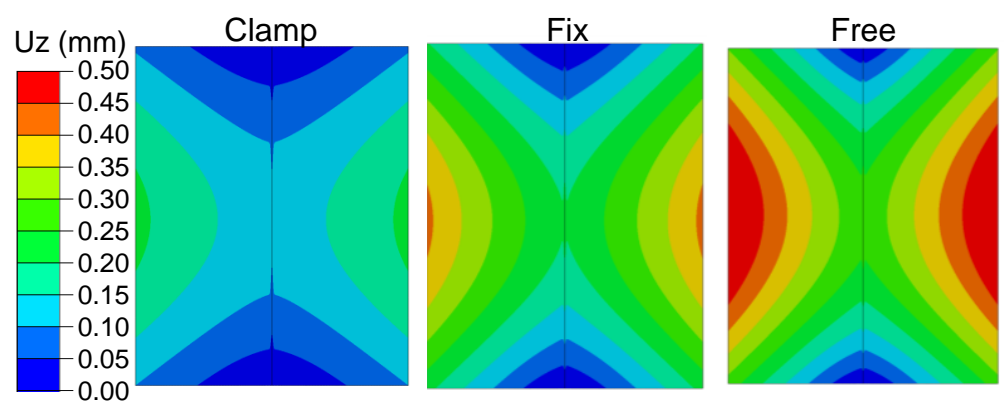

Figure 13 Contours of out of plane displacements on the top surface of butt welded joints under different mechanical boundary conditions

A comparison of the measured and predicted cambering and angular distortions is shown in Figure 14. For all mechanical boundary conditions, the out of plane displacement is symmetrical about the weld centre line and close to zero at the weld start and end positions, and the greatest on the outer edges at the mid-length of the specimen. The predicted maximum cambering distortion of more than $2.0 \mathrm{~mm}$ is observed without restraint, $1.4 \mathrm{~mm}$ when perfectly fixed around the outer edges and $1.3 \mathrm{~mm}$ when clamped close to the weld centre line compared to the experimental one of $1.8 \mathrm{~mm}$ for the actual clamping fixtures. The FE results without fixtures are overpredicted, whereas those with are underpredicted compared to the experimental data. A small difference is identified between the experimental and predicted values of around $0.4 \mathrm{~mm}$ or $22 \%$ difference for stronger restraints close to the weld region. Still, a similar trend in cambering distortion is observed both with measured and simulated distortion. In the case of angular distortions, the same pattern as that of cambering distortion is observed, where the specimen welded free of restraints overpredicted the maximum angular distortion of $2.1 \mathrm{~mm}$ compared to the experimentally measured value of $1.6 \mathrm{~mm}$, whereas, the specimens welded with fixtures under predicted with a value of $1.5 \mathrm{~mm}$ for weaker restraints around the outer edges and $1.1 \mathrm{~mm}$ for the clamping fixtures. This means that the minimum cambering and angular distortions are achieved with more restraints such as clamping close to the weld region. Although it is not possible to eliminate welding distortions, it could still be optimised by using the appropriate mechanical boundary conditions as shown above, and therefore, proved the significance of restraints to enhance the dimensional stability of welded structures. 

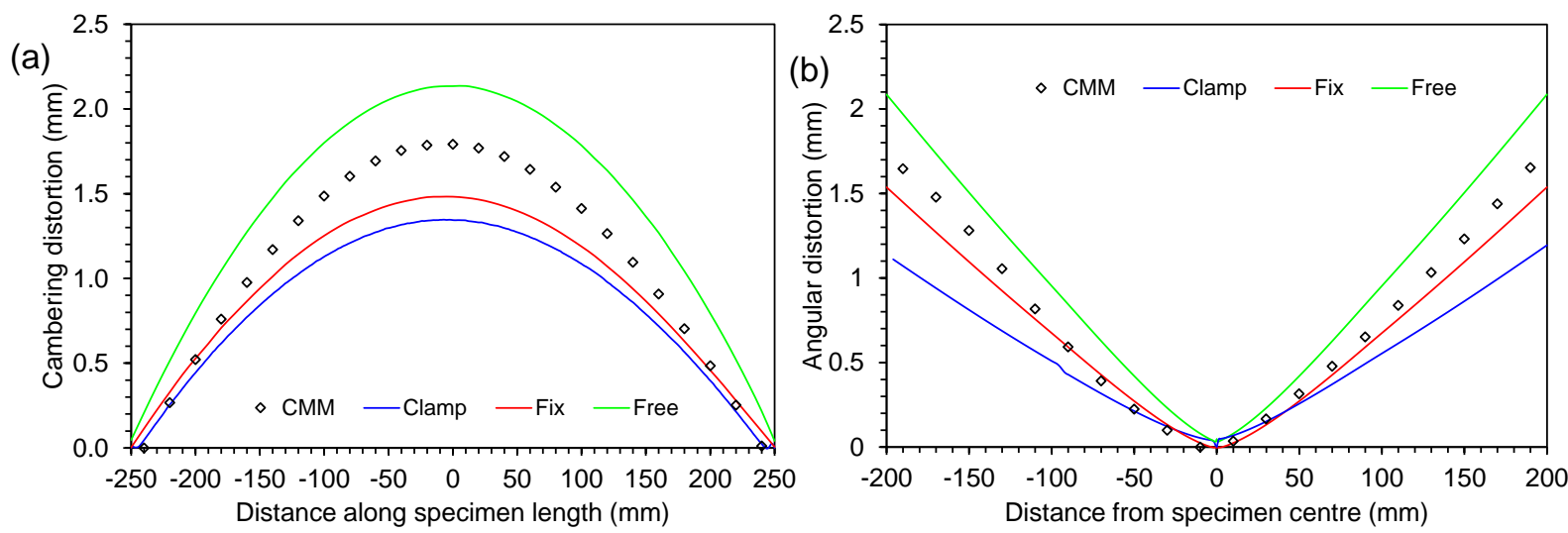

Figure 14 (a) Cambering and (b) angular out of plane displacements under different mechanical boundary conditions

\subsection{Effects of welding parameters on residual stresses and deformations}

The influence of welding process parameters including welding speed, laser power, heat input and the addition of filler metal was studied. Three different sets of welding parameters were investigated. For Model A, a laser power of $4.5 \mathrm{~kW}$ and a welding speed of $3.0 \mathrm{~m} / \mathrm{min}$ was used without filler metal. For Model B, a laser power of $2.9 \mathrm{~kW}$ and a welding speed of 1.5 $\mathrm{m} / \mathrm{min}$ was used also without filler metal. Finally, for Model C, the same laser power and welding speed as those of Model A was used but with a $1.0 \mathrm{~mm}$ diameter AA 4043 filler metal at a feed rate of $5.2 \mathrm{~m} / \mathrm{min}$.

\subsubsection{Simulated residual stresses and distortion}

Figure 15 and Figure 16 show the residual stress distributions for different sets of welding parameters used in FE simulations. It is evident that the magnitude and distribution of residual stresses are influenced by the welding parameters. The same trends in residual stresses in all three directions are observed for different welding parameters. Both the transverse and normal stresses are small even in the weld region as expected, with magnitudes of less than $30 \mathrm{MPa}$. Hardly any difference is observed with the normal stresses, whereas, the magnitude of compressive transverse stresses adjacent to the weld increases in the order of Model A, Model B and Model C. Model B which was welded using a lower laser power but slower welding speed than Model A, had similar but slightly higher total heat input per unit volume than Model A, which directly influenced the temperature distribution and consequently the residual stress distribution. 
(a)

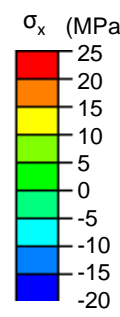

(b)
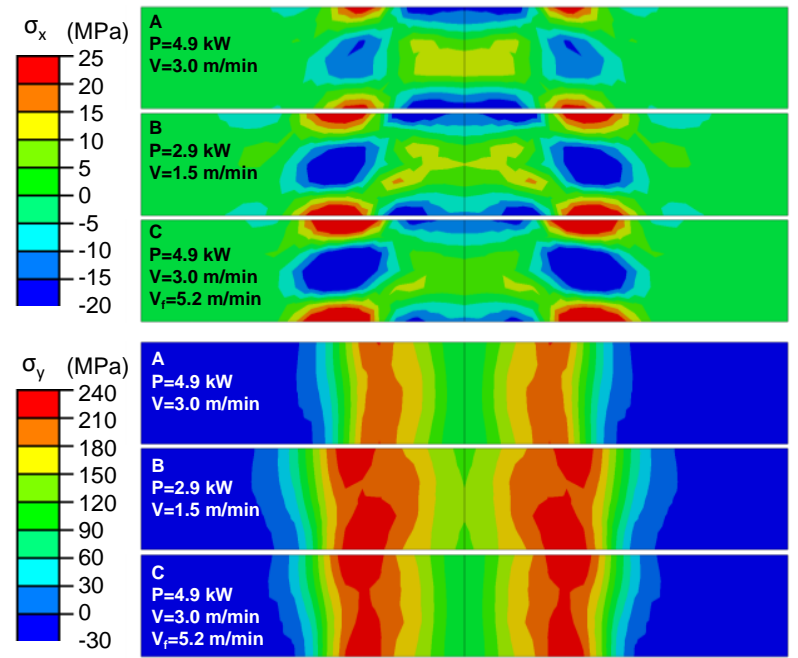

(c)
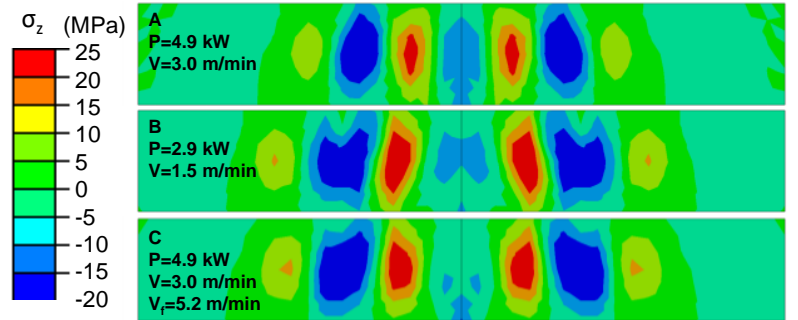
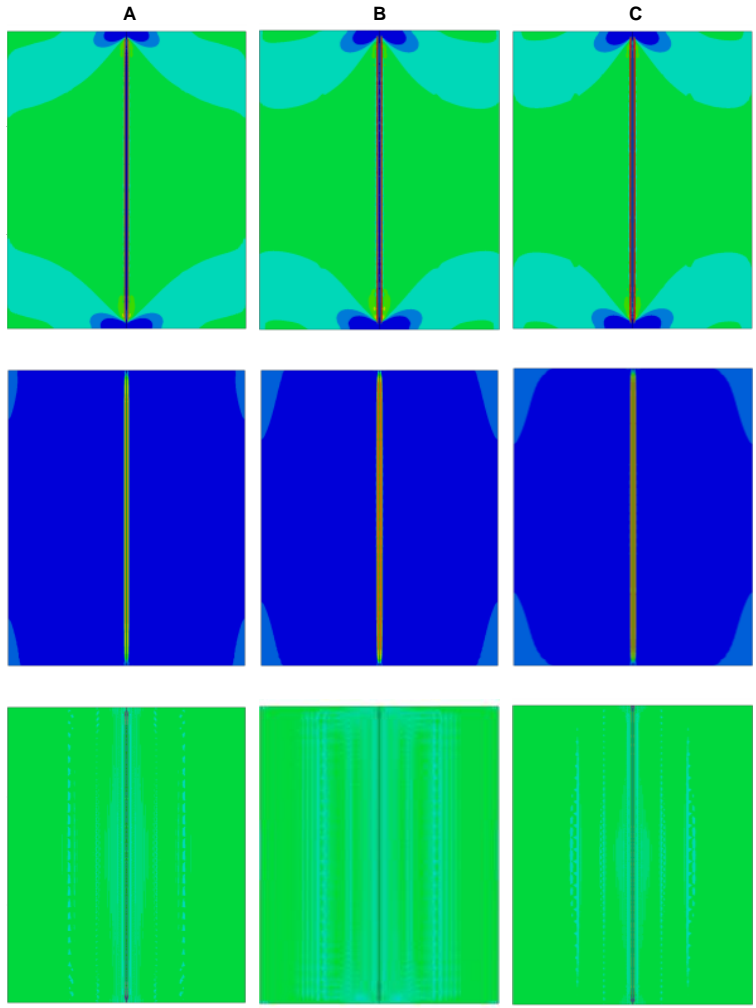

Figure 15 Contours of residual stress distribution on the weld transverse cross-section and top surface of butt welded joints in (a) $x$, (b) $y$ and (c) $z$ directions under different sets of welding parameters

More obvious variations in the residual stress distributions are observed in the longitudinal direction. The magnitude of the minimum tensile longitudinal stress at the weld centre line for Model B is higher than Model A and Model C by around $50 \mathrm{MPa}$. Model B which was welded using a reduced laser power and welding speed, in other words, less heat input compared to Model A and $\mathrm{C}$ led to a lower degree of softening in the weld. This means that the yield stress of the weld metal for Model B was larger than the other two. Therefore, the magnitude of the residual stresses was higher, equal to around $150 \mathrm{MPa}$ compared to around $100 \mathrm{MPa}$ for Model A and Model C. Figure 16 shows that the tensile residual stresses in the weld increase with increasing distance from the weld centre up to around $3 \mathrm{~mm}$, at which the peak value close to $250 \mathrm{MPa}$, comparable to the room temperature yield strength of the base metal, is reached. The longitudinal residual stresses then quickly drop to values close to zero within few millimetres and remain uniform across the entire width of the specimens. The width of the higher magnitude tensile region in and around the weld is the narrowest for Model A which also has the smallest weld width. In addition, the maximum longitudinal stress magnitude of around $240 \mathrm{MPa}$ located at the FZ/HAZ boundary is roughly $10 \mathrm{MPa}$ lower than that of Model B and Model C. The extent of the softening region is similar for all three cases but a considerable difference is observed in the peak tensile regions adjacent to 
the weld. This region is the smallest for Model A, wider for Model C and the widest for Model B. This could be attributed to increased heat conduction and wider temperature distribution of Model B due to its slower welding speed. Meanwhile, Model B and Model C have almost the same peak tensile stress magnitude as well as distribution. This shows that welding with filler metal also acts to increase the amount of heat absorbed into the workpiece during welding and effectively increases the overall energy input even though the same welding parameters as Model A were used.
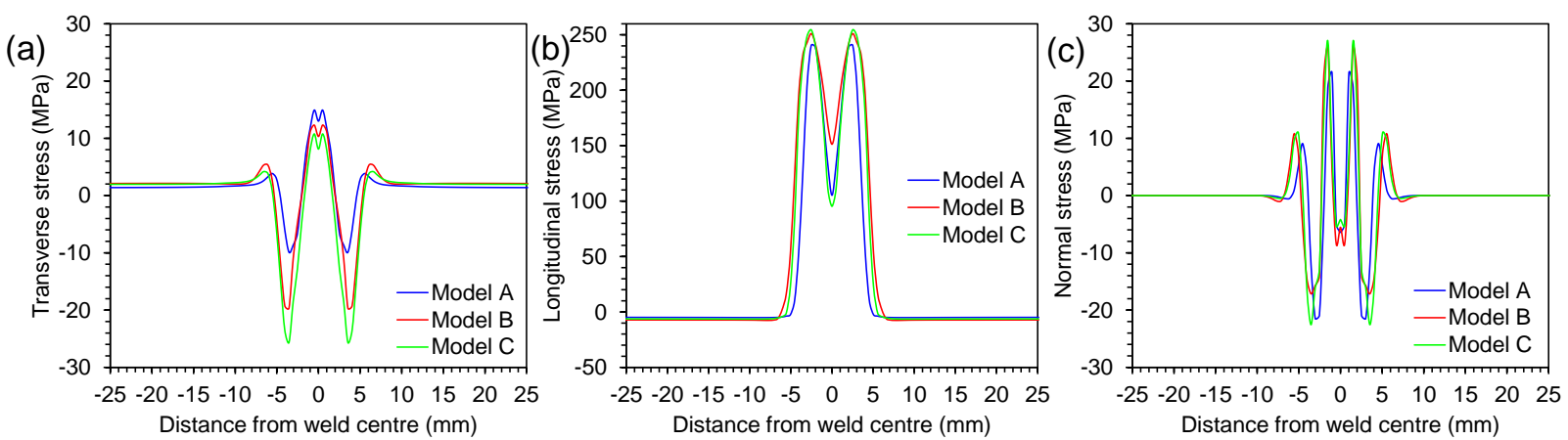

Figure 16 Residual stress distributions in (a) $x$, (b) $y$ and (c) $z$ directions under different sets of welding parameters

Contour plots of the numerically simulated out of plane displacement on the top surface of the sheets after welding are illustrated in Figure 17, showing the influence of using different combinations of welding parameters. The least distortion was observed in Model A, where the maximum displacement of around $0.2 \mathrm{~mm}$ was produced due to cambering along the longitudinal edges at mid-length in the welding direction. Decreasing both the laser power and welding speed while maintaining a similar heat input to Model A resulted in greater cambering and angular distortions on the edges of Model B but with only around $0.2 \mathrm{~mm}$ difference and a similar distribution. Such a difference relative to the length of 500 and the width of $400 \mathrm{~mm}$ was found to be negligible.

A

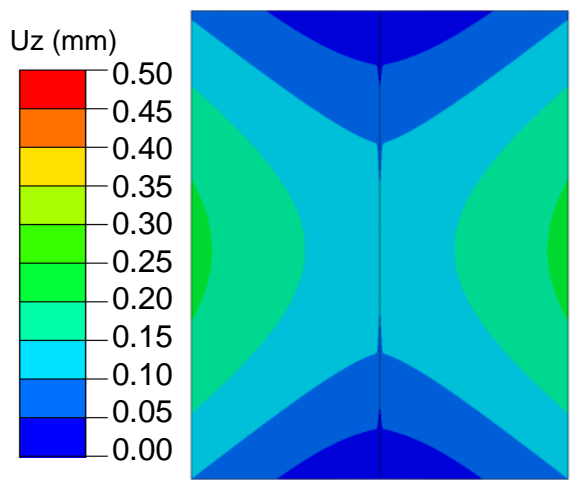

B

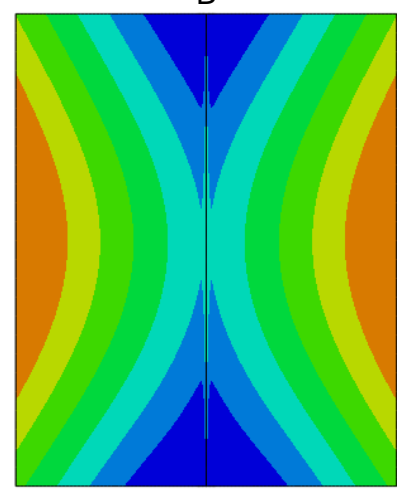

C

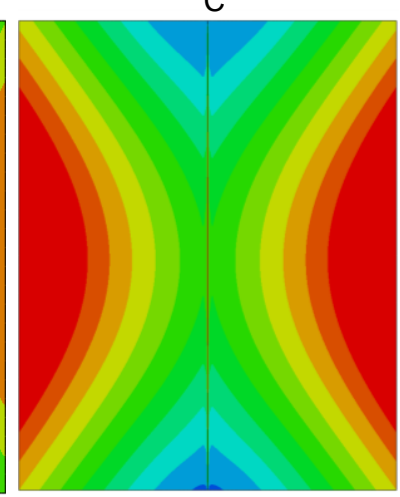

Figure 17 Contours of out of plane displacements on the top surface of butt welded sheets under different sets of welding parameters 
An approximately $0.5 \mathrm{~mm}$ maximum change in out of plane displacement between Model A and $\mathrm{C}$ was simulated, where the only in these two models was the filler metal deposition in Model C. Figure 18 (a) compares the simulated to experimentally measured cambering distortions using a coordinate measuring machine (CMM). While the simulated finite element analysis (FEA) values for Model A and B are overpredicted compared to the measured values for Model A and Model B they are still in good agreement. Both the CMM and FEA results show the same trend along the specimen length for both Model A and B but the measured maximum cambering distortion is less by around $0.2 \mathrm{~mm}$ for Model A and $0.6 \mathrm{~mm}$ for Model $\mathrm{B}$ than the simulated ones. In contrast, the maximum simulated cambering distortion of around $1.3 \mathrm{~mm}$ for Model $\mathrm{C}$ is underpredicted compared to the measured value of around 1.8 $\mathrm{mm}$. The maximum measured cambering distortion of greater than $1.5 \mathrm{~mm}$ for Model $\mathrm{C}$ are over double those of Model A and Model B. This indicates that welding with a filler metal can considerably increase the welding distortions as it is closely related to the energy input and weld microstructure. As previously shown in Figure 16, the magnitude of tensile longitudinal stresses in the weld are the lowest in Model C, welded with a filler metal. Therefore, increasing the weld metal dilution with filler material is expected to increase the welding distortion. Nevertheless, it is unavoidable to weld AA 2024-T3 with a filler metal in order to reduce solidification crack sensitivity. According to these results, it is still valid to weld with a filler metal as the welding distortion is still relatively small. Hence, a balance is required to control both the weld quality and distortions.
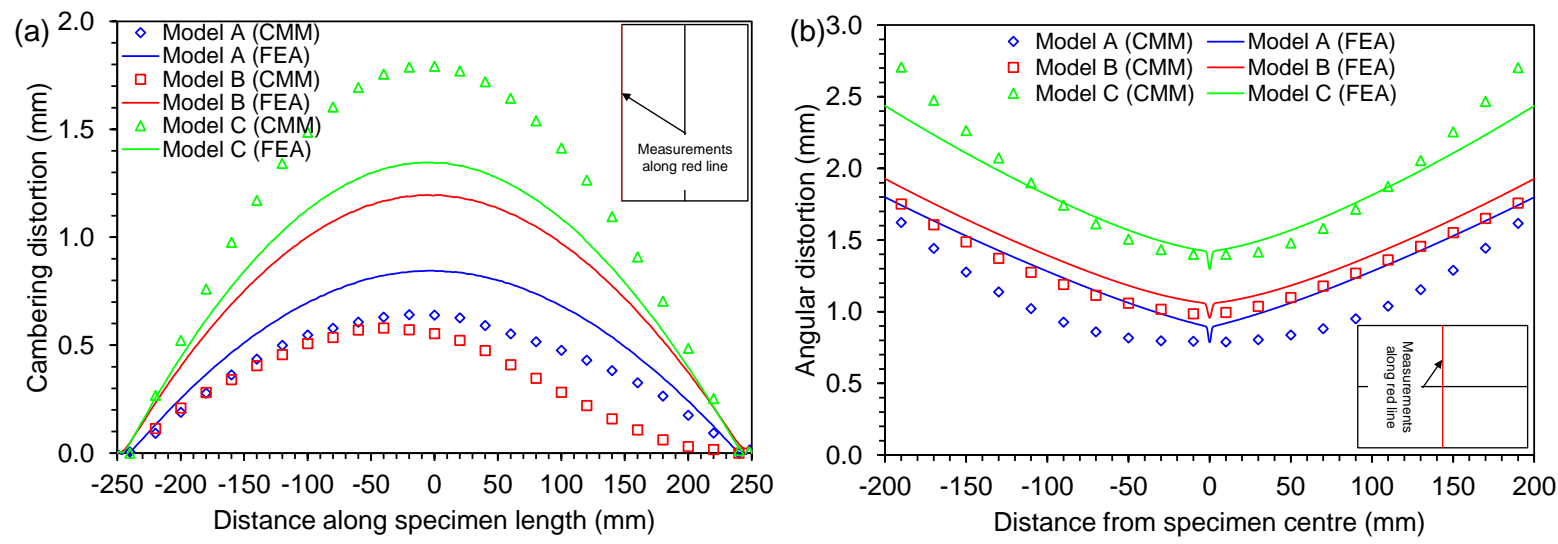

Figure 18 (a) Cambering and (b) angular out of plane displacements under different sets of welding parameters

The simulated and measured angular distortions as shown in Figure 18 (b) for all three models match very well compared to the cambering distortions. The maximum difference in angular distortion between the CMM and FEA results in Model C is only around $0.2 \mathrm{~mm}$ and also similar or even less in Model A and B. A shallower displacement gradient was measured 
in Model A, compared to the simulated one but the maximum angular displacement value is still similar, $1.6 \mathrm{~mm}$ and $1.8 \mathrm{~mm}$, respectively.

It can be concluded that welding parameters certainly have an influence on the residual stresses and distortion but only to a small extent as long as reasonable and optimised sets of welding parameters are used. The main differences found here are the magnitude of tensile residual stresses in the softened weld region and welding distortions due to different heat inputs caused by changing welding parameters and welding either with or without filler metal.

\subsubsection{Comparison between $\mathrm{X}$-ray diffraction and simulated results}

Surface residual stress measurements were taken using a low energy X-ray diffraction (XRD) technique on the top surface of butt welded AA 2024-T3 sheets, Model A, Model B and Model C, at a depth of around $30 \mu \mathrm{m}$ from the surface. Figure 19 shows the bi-axial residual stresses, transverse and longitudinal to the welding direction, measured using the XRD compared to numerically calculated stresses.

It was assumed that the residual stress distributions are symmetrical about the weld centre line and therefore, only half of the sheet was measured due to the limited time of measurement. Such assumption was valid as all the sheets were welded in a single pass with square groove weld configuration and without any weaving motion of the laser beam. It would be necessary to measure the stress distribution across the entire width in situations where multiple weld passes are used or an asymmetrical weld joint configuration is used. In addition, simulated stress distributions indicated that they are symmetrical about the weld centreline in all three directions. Both the experimentally measured and simulated transverse residual stresses as shown in Figure 19 are within the maximum range of less than $\pm 60 \mathrm{MPa}$ for all three welding conditions, which when compared to the yield strength of $345 \mathrm{MPa}$ were negligible. No obvious trend in the measured transverse stress distributions is observed for all three specimens and appear to be randomly scattered, whereas, numerical distributions show a small peak at the centre and troughs in the adjacent regions of less than $20 \mathrm{MPa}$ which eventually levelled out. It was therefore concluded that the stresses in the transverse direction are negligible in these thin sheets. 

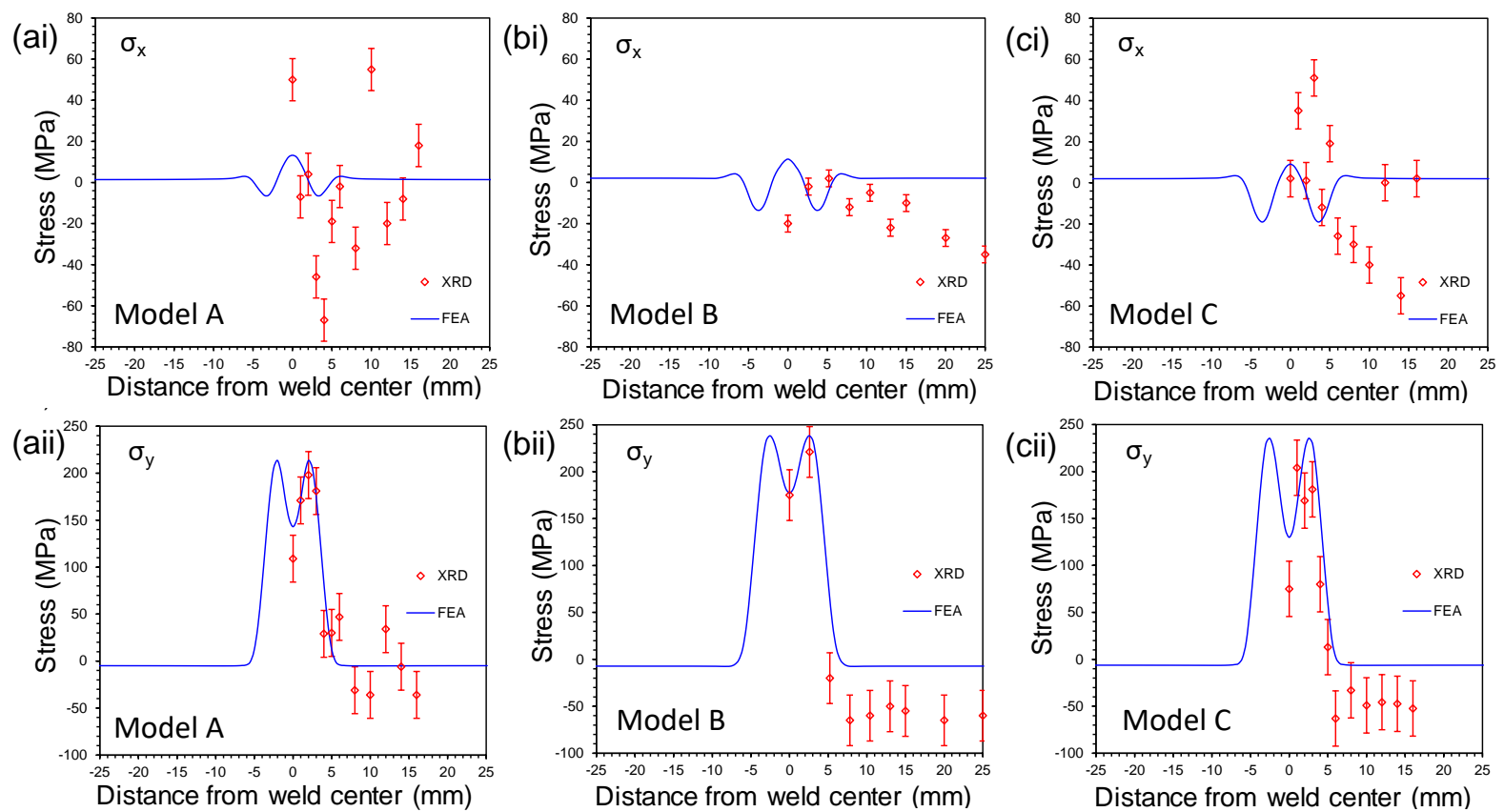

Figure 19 In-plane residual stress distributions on the top surface of butt welded AA 2024-T3 sheets in $x$ and $y$ directions measured using $X$-ray diffraction technique and from numerical simulations under three different sets of welding parameters (a) Model A, (b) Model B and (c) Model C

FE predictions on longitudinal residual stresses are in good agreement with the experimental measurements. The predicted stress distributions show large variations only up to around $5 \mathrm{~mm}$ away from the weld centre line and then level off to almost zero. The longitudinal stresses are significant even very close to the surface for both the simulated and experimental results. The simulated and experimental longitudinal stresses have approximately the same magnitude and distribution, reaching around $70 \%$ of the room temperature yield strength around the weld. Peak tensile longitudinal stresses of around 220-240 MPa are predicted and observed in a very narrow region adjacent to the weld at approximately 3-4 $\mathrm{mm}$ from the weld centre which quickly drops to below $0 \mathrm{MPa}$ and becomes weakly compressive at distances greater than $5 \mathrm{~mm}$ from the weld centre. The experimental results indicate larger compressive stresses away from the weld at distances greater than around $5 \mathrm{~mm}$ from the weld centre than the predicted stresses, with the maximum difference of around $60 \mathrm{MPa}$. However, uncertainty in measurements as shown by the error bars means that such differences are acceptable.

The stress distributions and magnitudes are similar among all three but minor differences are observed at the weld centre and in terms of the width of the tensile region which corresponds to the width of fusion boundaries. More importantly, softening or a heat affected weakening effect at the middle position in the weld, showing a drop at the centre is captured both in the 
experimental and numerical results, where a small dip is identified at the weld centre as shown in Figure 19. It was found that the lowest stress magnitude is measured and calculated in the specimen welded with filler metal, Model C, which means that this specimen experienced softening the most. The measured value of around $70 \mathrm{MPa}$ is lower than the calculated minimum value of around $120 \mathrm{MPa}$ at the weld centre. Similarly, the measured value at the weld centre of around $100 \mathrm{MPa}$ for Model A is also slightly lower than the calculated value of around $130 \mathrm{MPa}$. On the other hand, the largest value is measured in Model B of around $170 \mathrm{MPa}$, which is in good agreement with the calculated value of also around $170 \mathrm{MPa}$. The peak tensile longitudinal stresses are the greatest in Model B of around $230 \mathrm{MPa}$, which was welded using a lower laser power and slower welding speed, compared

to Model A and Model C. Nevertheless, it was concluded that the predicted stress magnitudes and distributions illustrated in Figure 19 are in good agreement with the measured results. As mentioned earlier, it seems too conservative to assume that yield magnitude residual stresses occur in AA 2024-T3 laser welds.

\subsubsection{Comparison between neutron diffraction and simulated results}

Residual stresses in Model A were measured and calculated using the neutron diffraction technique from a reactor based diffractometer E3 at HZB. Figure 20 shows the residual stress distributions obtained from the $\{222\}$ and $\{311\}$ reflections for aluminium compared to the results from numerical simulations. The choice of diffraction elastic constants $\mathrm{E}$ and $v$ depended on the crystallographic hkl plane used for strain measurements. Since crystallographic anisotropy of the elastic constants is small for aluminium, the values of $\mathrm{E}=70.2 \mathrm{GPa}$ and $v=0.35$ were used for both the $\mathrm{Al}\{222\}$ and $\{311\}$ reflections to calculate the stresses. The stresses were obtained via three different methods. For the first set of measurements, local stresses were calculated based on strain-free lattice parameters obtained from a stress-free reference comb with thin teeth from the weld region where macroscopic stresses are known to relax. Alternatively, a far-field global reference value obtained from a position which was regarded as stress-free was used to calculate stresses. Finally, a plane stress condition was assumed, where the normal stress component was set to zero and therefore, the transverse and longitudinal stresses were determined using the biaxial formula. Figure 20 shows that the stresses obtained from the $\{222\}$ and $\{311\}$ peaks are not quite the same. The cause of such difference is likely due to the influence of microscopic stress on the stress results. While the $\{311\}$ diffraction peak gives good measure for the macro-stresses, the $\{222\}$ peak, on the other hand, may be affected by intergranular stresses which cause the 
elastic lattice strain for this reflection to differ from the true macroscopic elastic strain. Considerable differences are observed between the two reflections for the longitudinal stresses, whereas, the differences for the transverse and normal stresses are relatively small. It is clear from both results that the contributions from the transverse and normal residual stresses are much smaller than that of the longitudinal residual stresses, within the range between 100 and $-100 \mathrm{MPa}$.

The results obtained from plane stress condition, globally applied reference parameter and local stress-free parameters are all in good agreement and match the FE predictions well. There are no significant differences among these results and even the plane stress assumption gives reasonable stress distributions. The results from the $\{311\}$ reflection match the FE results better than those from the $\{222\}$ reflection, which overpredicted the longitudinal stresses in the weld region. The $\{222\}$ longitudinal stresses match the FE results best within the first $5 \mathrm{~mm}$ from the weld centre when stress-free lattice parameters from the comb sample were used, but indicate greater compressive stresses further away than the FE predictions.

Using the plane stress condition also produces similar results, whereas, globally applied reference parameters leads to further overprediction of longitudinal stresses by almost 100 MPa more than the FE predictions. The $\{222\}$ stresses also show larger uncertainties than the $\{311\}$ stresses so these variations cannot be neglected. On the other hand, the $\{311\}$ longitudinal stresses are in good agreement with the predicted stresses for all three calculation methods.

Both the magnitude and distribution of longitudinal stresses in and around the weld are well matched and only small variability of stress measurements is observed. The peak longitudinal stresses were measured to be close to $200 \mathrm{MPa}$ at around $3 \mathrm{~mm}$ from the weld centre, like those of the FE model and then drop to zero at a similar rate at around $6 \mathrm{~mm}$ away from the weld centre. The minimum tensile longitudinal stresses of around $50 \mathrm{MPa}$ were measured at the weld centre when using either global or local lattice parameters, which are lower than the FE stresses, whereas those from the plane stress condition are similar, approximately 100 $\mathrm{MPa}$. This proves the importance of using local stress-free lattice parameters to capture precisely the lower longitudinal residual stresses due to softening of the weld metal. In contrast, the longitudinal stresses obtained under plane stress condition match the FE predictions better than the other two in the compressive region far from the weld, whereas, the opposite is true for transverse stresses. 

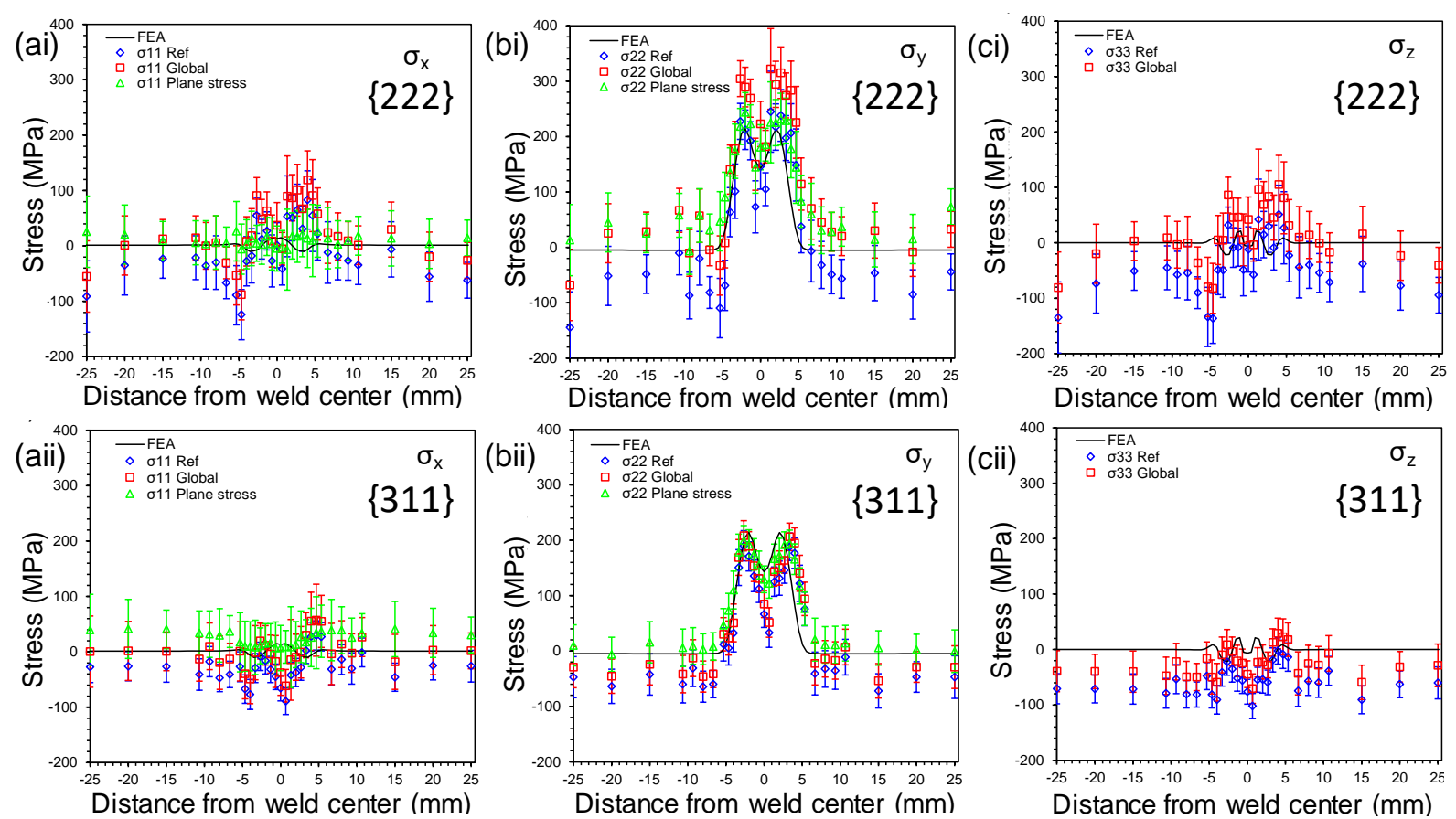

Figure 20 Residual stress distributions in $x, y$ and $z$ directions measured experimentally in (a) $\{222\}$ and (b) $\{311\}$ hkl planes for Model A from reactor-based diffractometer E3 and calculated using either plane stress assumption, globally applied far-field reference value or local stress-free value from reference sample compared to numerically simulated residual stress distributions

Residual stresses in Model B and Model C were measured and calculated using neutron diffraction technique from a pulsed spallation source ENGIN-X at ISIS. Residual stresses calculated using this instrument were not specific to a particular peak but instead obtained by fitting an average lattice spacing to the whole diffraction pattern using the Rietveld (or Pawley-Rietveld) technique. The strain calculated using this method is known to give a value close to the macroscopic strain in both elastic and plastic region so the macroscopic bulk elastic constants were used to determine the stress.

As it can be seen from Figure 21 and Figure 22, large stress gradients exist within a very narrow region around the weld and almost stress-free in the rest of the regions. Again, the measured transverse and normal stresses are very small, typically much less than $100 \mathrm{MPa}$ in either tension or compression, and in good agreement with the predicted stresses for both Model B and Model C under all three conditions. Figure 22 shows that the specimen Model C clearly has some compressive stresses in the weld as much as $-100 \mathrm{MPa}$, whereas, predicted stresses show almost no compressive behaviour in this region. The longitudinal stresses derived from neutron diffraction measurements resemble the numerically determined stresses. The peak tensile longitudinal residual stresses are in the range between 200 and $300 \mathrm{MPa}$ depending on the method used to calculate the stresses. A lower tensile longitudinal residual stress at the weld centre of around $60 \mathrm{MPa}$ is obtained when using local stress-free lattice 
parameters compared to over $100 \mathrm{MPa}$ when using a global value or assuming plane stress condition. Similarly, higher peak tensile longitudinal residual stresses of around $250 \mathrm{MPa}$ are obtained around the weld when using the local stress-free lattice parameters compared to the other two cases which are less by around $50 \mathrm{MPa}$.
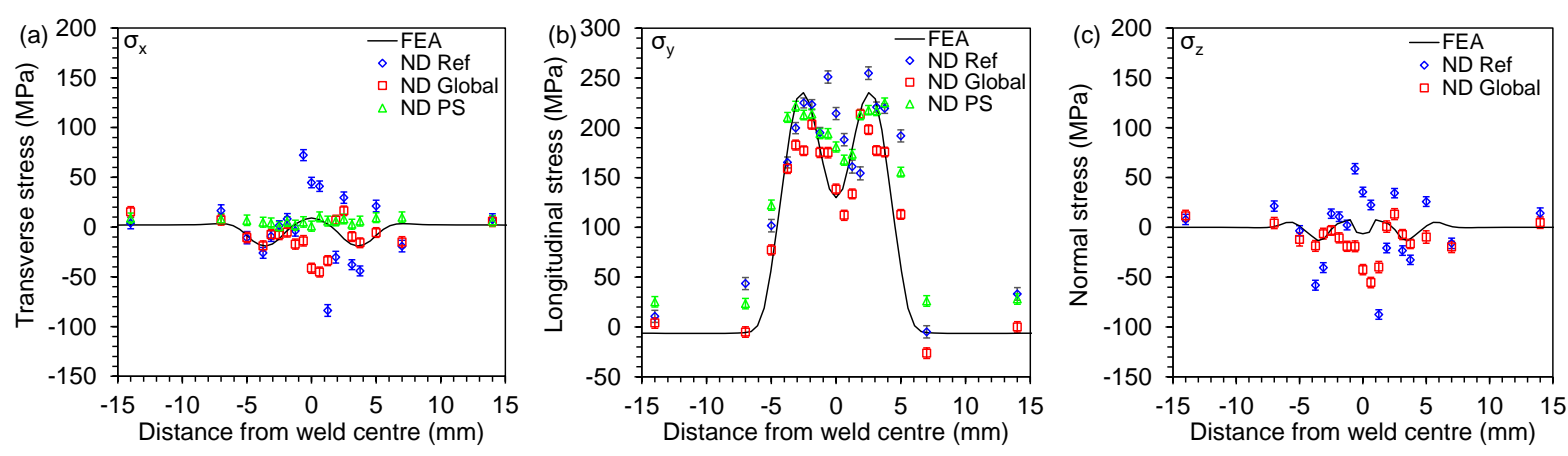

Figure 21 Residual stress distributions in (a) $x$, (b) $y$ and (c) $\mathrm{z}$ directions measured experimentally using neutron diffraction technique for Model B from pulsed spallation source ENGIN-X fitted with Rietveld refinements and calculated using either a plane stress assumption, globally applied far field reference value or local stress free values from a reference sample compared to numerically simulated residual stress distributions

Model $\mathrm{C}$ was welded with filler metal to control the weld microstructure and improve the weld quality. Filler metal has a considerable influence on the weld metal chemical composition so the effect of weld metal chemical compositional and microstructural variations on intergranular stresses must be accounted for if accurate strains are to be measured in this region. Figure 22 shows that when such variations are not considered in the stress calculations as in the case of using a globally applied reference parameters, the longitudinal residual stresses at the weld centre are no longer tensile in nature but instead close to zero. On the other hand, when local stress-free lattice parameters from a reference comb are used, then the longitudinal stresses become considerably higher, as high as 100 MPa. Likewise, under a plane stress condition, stress magnitudes over $100 \mathrm{MPa}$ are found at the weld centre. For this reason, it is crucial to consider the chemical compositional and microstructural variations across the weld when welded with filler metal by choosing the right stress-free reference lattice parameters which remove these effects. 

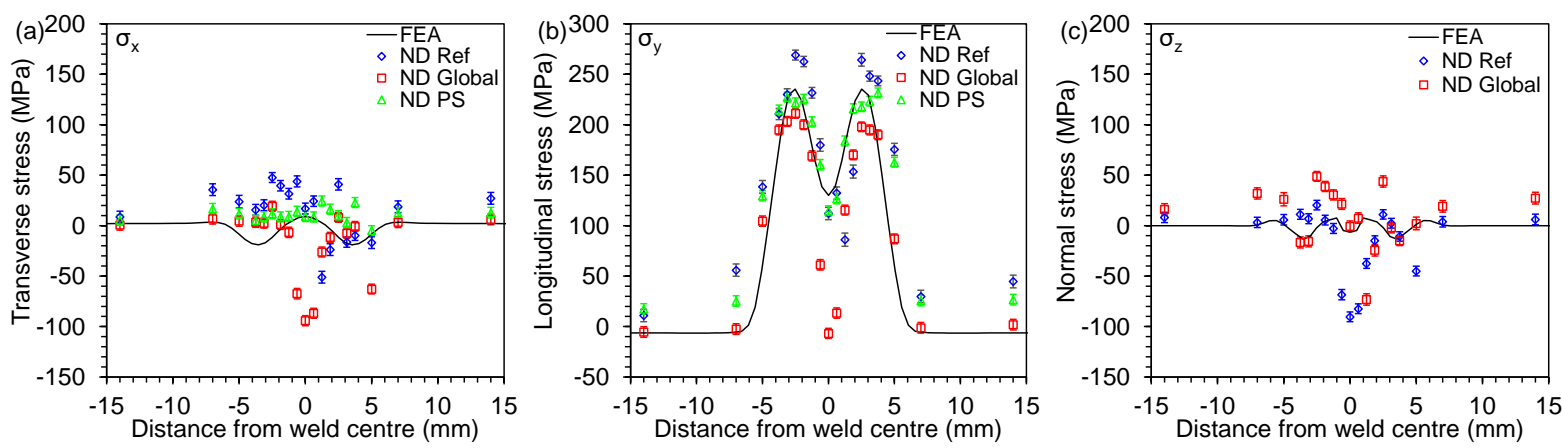

Figure 22 Residual stress distributions in (a) $\mathrm{x}$, (b) $\mathrm{y}$ and (c) $\mathrm{z}$ directions measured experimentally using neutron diffraction technique for Model $\mathrm{C}$ from pulsed spallation source ENGIN-X fitted with Rietveld refinements and calculated using either a plane stress assumption, globally applied far field reference value or local stress free values from a reference sample compared to numerically simulated residual stress distributions 


\section{Conclusions}

Numerical simulation results of the weld mechanical analysis showed good agreement in general with the experimental results in terms of the residual stress distributions and magnitudes. The welded specimens were characterised by a more pronounced dominance of longitudinal residual stresses over transverse and normal residual stresses. The longitudinal residual stresses in all the cases were very high but not as high as the yield strength of the material at room temperature. They were largely tensile in nature only within the FZ or HAZ and tended to be weakly compressive in the rest of the specimen.

Mechanical boundary condition had a relatively small influence on residual stresses in thin sheets of butt welded specimens. Welding distortion was clearly influenced by the clamping conditions, where the minimum distortion was induced by clamping close to the weld without affecting the residual stresses significantly in the butt-welded specimens.

Welding parameters were found to influence the residual stress fields. Welding with filler metal resulted in a wider tensile region, higher peak tensile and compressive stress magnitudes around the weld and lower stresses in the softened weld metal. Similarly, greater out of plane displacements were detected when welding with filler metal. Heat input per unit volume was also found to be an influential parameter for the control of residual stress levels.

The observed deviations in the peak longitudinal stress levels in AA 2024-T3 specimens were mainly caused by the stress-free lattice parameters used when processing the elastic strains from the neutron diffraction measurements. The magnitude of experimentally determined reduced longitudinal tensile residual stresses in the softened weld region of AA 2024-T3 specimens was largely controlled by the chosen stress-free state. The use of a global far field lattice parameter resulted in under predicting these stresses for the butt weld AA 2024-T3 specimen welded with filler metal because the influence of chemical compositional and microstructural variations in the weld was not accounted for in this case, whereas, the use of local values or plane stress condition led to the prediction of higher stresses.

The measured residual stresses were also dependent on the crystallographic hkl plane from which they were obtained from and the cause of such difference was found to be due to the presence of microscopic stresses. In the case of AA 2024-T3 specimens, both the $\{222\}$ and $\{311\}$ peaks were detected at the same time for Model A. The $\{311\}$ peak on average 
produced higher stress magnitudes due to the reason above. On the other hand, for the specimens Model B and Model C, the entire diffraction spectrum was fitted with Rietveld refinements instead of conducting a single peak analysis so it was possible to use the macroscopic elastic constants and the results were in good agreement with the numerical results.

\section{Acknowledgement}

The strong support from the Aviation Industry Corporation of China (AVIC) and Beijing Aeronautical Manufacturing Technology Research Institute (BAMTRI) for this funded research is much appreciated. The research was performed at the AVIC Centre for Structural Design and Manufacture at Imperial College London. Finite element analysis results were obtained from work conducted on the Imperial College High-Performance Computing Service (doi: 10.14469/hpc/2232). Dr C M Davies acknowledges the support of EPSRC under grant number EP/I004351/1. This research project has been supported by the European Commission under the 7th Framework Programme through the 'Research Infrastructures' action of the 'Capacities' Programme, CP-CSA_INFRA-2011-1.1.17 Number 233883 NMI3 II. We thank HZB and ISIS for the allocation of neutron radiation beam time. 


\section{References}

1. Ding RG, Ojo OA, Chaturvedi MC (2006) Fusion zone microstructure of laser beam welded directionally solidified Ni3Al-base alloy IC6. Scr Mater 54:859- 864. doi:

10.1016/j.scriptamat.2005.11.010

2. Katayama S, Kawahito Y, Mizutani M (2012) Latest Progress in Performance and Understanding of Laser Welding. Phys Procedia 39:8-16 . doi: 10.1016/j.phpro.2012.10.008

3. Dittrich D, Standfuss J, Liebscher J, et al (2011) Laser beam welding of hard to weld Al alloys for a regional aircraft fuselage design- First results. Phys Procedia 12:113-122 . doi:

10.1016/j.phpro.2011.03.015

4. Chen L, He E, Ahn J, Dear J (2014) Parametric optimization and joint heterogeneity characterization of fiber laser welding of AA2024-T3. In: Proceedings of the 67th Annual Assembly of the International Institute of Welding. International Institute of Welding, Seoul, KR, pp 1-9

5. Ahn J, Chen L, Davies CM, Dear JP (2014) Digital Image Correlation for Determination of Local Constitutive Properties of Fibre Laser Welding Joints in AA2024-T3. In: Proceedings of the 16th International Conference on Experimental Mechanics. University of Cambridge, Cambridge, GB, pp 12

6. Ahn J, He E, Chen L, et al (2017) The effect of Ar and He shielding gas on fibre laser weld shape and microstructure in AA 2024-T3. J Manuf Process 29:62-73 . doi: 10.1016/j.jmapro.2017.07.011

7. Ahn J, Chen L, He E, et al (2017) Effect of filler metal feed rate and composition on microstructure and mechanical properties of fibre laser welded AA 2024-T3. J Manuf Process 25:26-36 . doi: 10.1016/j.jmapro.2016.10.006

8. ISO Standard 13919-1, 2011, "Welding — Electron and laser-beam welded joints — Guidance on quality levels for imperfections — Part 1: Steel”, ISO, 2011, www.iso.org.

9. ISO Standard 13919-2, 2011, "Welding — Electron and laser-beam welded joints — Guidance on quality levels for imperfections — Part 2: Aluminium and its weldable alloys”, ISO, 2011, www.iso.org.

10. AWS D17.1 Specification for fusion welding for aerospace applications

11. Zink W (2000) Integral solutions for fuselage shells. In: Peters M, Kaysser WA (eds) Proceedings of the 19th European Conference on Advanced Aerospace Materials-Materials for Aerospace Applications. DGLR-Bericht, Munich, pp 25-35

12. Liu J, Watanabe I, Yoshida K, Atsuta M (2002) Joint strength of laser-welded titanium. Dent Mater 18:143-148 . doi: 10.1016/S0109-5641(01)00033-1

13. Park MK, Sindhu RA, Lee SJ, et al (2009) A Residual Stress Evaluation in Laser Welded Lap Joint with Hole Drilling Method. Int J Precis Eng Manuf 10:89-95

14. DebRoy T, David SA (1995) Physical processes in fusion welding.pdf. Rev Mod Phys 67:85 
15. Flores-Johnson EA, Muránsky O, Hamelin CJ, et al (2012) Numerical analysis of the effect of weldinduced residual stress and plastic damage on the ballistic performance of welded steel plate. Comput Mater Sci 58:131-139 . doi: 10.1016/j.commatsci.2012.02.009

16. Masubuchi K (1980) Distortion in Weldments. In: Analysis of Welded Structures: Residual Stresses, Distortion, and their Consequences. Pergamon Press Ltd., Oxford, pp 235-327

17. Masubuchi K (1980) Fundamental Information on Residual Stresses. In: Analysis of Welded Structures: Residual Stresses, Distortion, and their Consequences. Pergamon Press Ltd., Oxford, pp 94-111

18. Saad G, Fayek SA, Fawzy A, et al (2010) Deformation characteristics of Al-4043 alloy. Mater Sci Eng A 527:904-910 . doi: 10.1016/j.msea.2009.09.018

19. Ahn J, He E, Chen L, et al (2017) Prediction and measurement of residual stresses and distortions in fibre laser welded Ti-6Al-4V considering phase transformation. Mater Des 115:441-457 . doi: 10.1016/j.matdes.2016.11.078

20. Davison R, Bland JA (1986) Generalized regression for CMMs. Int J Math Educ Sci Technol 17:305309 . doi: 10.1080/0020739860170305

21. Bayraktar FS, Staron P, Koçak M, Schreyer A (2008) Analysis of Residual Stress in Laser Welded Aerospace Aluminium T-Joints by Neutron Diffraction and Finite Element Modelling. Mater Sci Forum 571-572:355-360 . doi: 10.4028/www.scientific.net/MSF.571-572.355

22. Radaj D (2003) Modelling of welding residual stresses and distortion. In: Welding residual stresses and distortion: Calculation and measurement, 2nd ed. DVS-Verlag GmbH, Düsseldorf, pp 100-272

23. Davies CM, Ahn J, Tsunori M, et al (2015) The Influence of Pre-existing Deformation on GMA Welding Distortion in Thin Steel Plates. J Mater Eng Perform 24:261-273 . doi: 10.1007/s11665-014-1313-0

24. Dean SW, Croucher T (2009) Minimizing Machining Distortion in Aluminum Alloys through Successful Application of Uphill Quenching-A Process Overview. J ASTM Int 6:101770 . doi:

10.1520/JAI101770 